\title{
Endogenous and exogenous galectin-3 promote the adhesion of tumor cells with low expression of MUC1 to HUVECs through upregulation of $\mathrm{N}$-cadherin and CD44
}

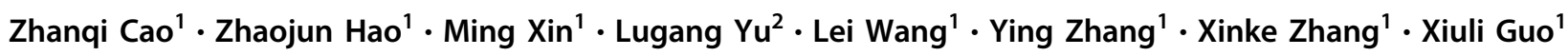

Received: 19 January 2018 / Revised: 29 June 2018 / Accepted: 16 July 2018 / Published online: 31 August 2018

(c) United States \& Canadian Academy of Pathology 2018

\begin{abstract}
Tumor cell-endothelial adhesion is one of the key steps in tumor cell haematogenous dissemination in metastasis and was previously shown to be mediated by interaction of galectin-3 with the transmembrane mucin protein MUC1. In this study, the effect of exogenous as well as endogenous galectin-3 on adhesion of two cell lines (low MUC1-expressing human prostate cancer PC-3M cells and non-small-cell lung cancer A549 cells) to monolayer of umbilical vein endothelial cells (HUVECs) was investigated. We found that suppression of endogenous galectin-3 expression reduced tumor cell adhesion to HUVECs and also decreased cell invasion and migration. Exogenous galectin-3 promoted tumor cell adhesion to HUVECs by entering cells. Both exogenous and endogenous galectin-3 upregulated the expression of $\beta$-catenin and increased $\beta$ catenin nuclear accumulation, and subsequently upregulated the expression of $\mathrm{N}$-cadherin and CD44. We deduced that both exogenous as well as endogenous galectin-3 promoted low MUC1-expressing cancer cell adhesion to HUVECs by increasing the expression of $\mathrm{N}$-cadherin and CD44 via an increase of nuclear $\beta$-catenin accumulation. These results were confirmed further by using a $\beta$-catenin/TCF transcriptional activity inhibitor, N-cadherin or CD44 siRNAs. Taken together, our results suggest a new molecular mechanism of galectin-3-mediated cell adhesion in cancer metastasis.
\end{abstract}

\section{Introduction}

Galectin-3 (Gal-3) is a $29-\mathrm{kDa} \beta$-galactoside-binding protein and was first identified on murine thioglycollate-elicited peritoneal macrophages [1]. Gal-3 is the only member of the chimeric type of galectins and is expressed intracellularly and extracellularly by various cell types [2]. It is composed of a carbohydrate recognition domain at the $\mathrm{C}$-terminal and

These authors contributed equally: Zhanqi Cao, Zhaojun Hao.

Electronic supplementary material The online version of this article (https://doi.org/10.1038/s41374-018-0119-3) contains supplementary material, which is available to authorized users.

Xiuli Guo

guoxl@sdu.edu.cn

1 Department of Pharmacology Drug Screening Platform of Shandong Province Center for Drug R\&D, School of Pharmaceutical Sciences, Shandong University, 250012 Jinan, China

2 Department of Gastroenterology, Institute of Translational Medicine, University of Liverpool, Liverpool L69 3GE, UK a long repetitive collagen-like sequence at the N-terminal domain which is sensitive to proteolysis by MMP-2 and MMP-9 [3]. In addition, Gal-3 is able to dimerize and polymerize under some specific conditions, such as at high concentration or the presence of ligands. It is synthesized in the cytoplasm and can also be secreted into extracellular environment where it is involved in many biological functions, such as immune regulation, apoptosis, cell adhesion, mRNA splicing and embryogenesis.

Recent studies show that both endogenous and exogenous Gal-3 are involved in angiogenesis, cancer cell adhesion, proliferation and metastasis. Endogenous Gal-3 is upregulated in various cancer cells, such as breast cancer, colon cancer, gastric cancer, lung cancer, and liver cancer [4-6] and plays an important role in cell invasion, apoptosis, transcription, mRNA splicing, and cell growth. An early study shows that cytoplasmic Gal-3 inhibited apoptosis by binding to B-cell lymphoma 2 (Bcl-2) [7]. Endogenous Gal-3 was also shown to increase nuclear $\beta$ catenin accumulation by regulation of GSK-3 $\beta$ activity, and promote colon cancer cells progression [8]. The concentrations of Gal-3 in the serum from patients with breast, lung, gastrointestinal, head and neck or ovarian 
cancer, melanoma and pancreatic cancer were higher than that in serum from healthy individuals. The level of circulating galectin-3 was higher in the serum of cancer patients those with metastasis [9]. Higher circulating Gal3 is considered a potential biomarker for colorectal cancer metastasis [10]. Extracellular Gal-3 is associated with tumor cell dissemination, survival, cancer-matrix adhesion, cancer-endothelial adhesion, angiogenesis and cell growth through interaction with cell surface glycans such as MUC1 [11, 12] and integrins [7, 13].

Cell adhesion molecules (CAMs) are a group of transmembrane proteins, each of which is composed of extracellular, transmembrane and cytoplasmic domains. CAMs are divided into five groups including integrins, cadherins, selectins and lymphocyte homing receptors and the immunoglobulin superfamily (Ig-SF). Exogenous Gal-3 was reported to regulate cell adhesion through interaction with $\mathrm{N}$-cadherin, GM1 ganglioside, Mgat5-modified N-glycans, fibronectins, laminin, collagen IV, and elastin [4, 14-18]. Moreover, Gal-3 was demonstrated to promote polarization of the transmembrane mucin protein MUC1 by binding to the carbohydrate TF (Gal $\beta 1$,3galNAc $\alpha-)$ antigen. MUC1 polarization by Gal-3 exposes the cadherin molecules, leading to increase cancer cell adhesion to vascular endothelial cells $[11,19]$. However, effect of extracellular Gal-3 on adhesion of tumor cells with low expression of MUC1 to vascular cells is unknown.

In the present study, we found that endogenous Gal-3 promoted adhesion of tumor cells to HUVECs through upregulation of the expression of CAMs, N-cadherin and $\mathrm{CD} 44$, an effect was found to be partly mediated by nuclear accumulation of $\beta$-catenin in human non-small-cell lung cancer A549 cells. Exogenous introduction of recombinant Gal-3 was taken up by low Gal-3-expressing human prostate cancer PC-3M cells and high Gal-3-expressing A549 cells and resulted in an increase cell $\beta$-catenin nucleus accumulation and cell adhesion to HUVECs.

\section{Materials and methods}

\section{Materials}

RPMI-1640 medium, Ham's F-12K (Kaighn's) medium, fetal bovine serum and L-glutamine were purchased from GINCO BRL (Grand Island, NY, USA). Endothelial cell medium (ECM) were purchased from ScienCell (San Diego, CA, USA). Monoclonal antibodies (mAb) against human Gal-3, MMP-2, MMP-9 and $\beta$-catenin were purchased from Cell Signaling Technology (Boston, MA, USA). Rabbit Polyclonal antibodies against MUC1, CD44 and N-cadherin were from Proteintech Group, Inc (Chicago,
IL, USA). Recombinant full-length human galectin-3 was from Abcam (Cambridge, UK). ICG-001 was from Aladdin Aladdin Reagent Company (Shanghai, China). ECL reagent, Membrane and Cytosol Protein Extraction Kit and Immunol Fluorence Staining Kit was from Beyotime (Shanghai, China). Subcellular Structure of Cytoplasm and Cell Nucleus Extraction Kit was from Boster Biological Technology (Wuhan, China). Bovine serum albumin (BSA), Vybrant DiO Cell labeling Solutions, radio immunoprecipitation assay (RIPA) lysis buffer and phenylmethane sulfonyl fluoride (PMSF, $100 \mathrm{mmol} / \mathrm{l}$ ) were purchased from Solarbio (Beijing, China). Gal-3 and Ncadherin siRNAs were purchased from GenePharma Corporation (Shanghai, China). The coding strand targeting by Gal-3 siRNA duplex was 5'-CAC GCT TCA ATG AGA ACA ACA-3' and N-cadherin siRNA duplex was $5^{\prime}$-CTA ACA GGG AGT CAT ATG GTG GAGC- $3^{\prime}$. The control siRNA was 5'-TTC TCC GAA CGT GCT GTC TTT-3'. CD44 siRNA was purchased from Santa Cruz Biotechnology (CA, USA). Lipofectamine 2000 Reagent, TRIzol Reagent and Opti-MEM Culture Medium were purchased from Invitrogen (Carlsbad, CA, USA). Both MUC1 mRNA and $\beta$-actin mRNA were synthesized by GenePharma Corporation (Shanghai, China). qPCR RT Kit and SYBR Green Real-time PCR Master Mix were purchased from TOYOBO (Japan). XenoLight D-Luciferin Potassium Salt was purchased from Caliper Life Sciences (Hopkinton, MA, USA). Culture dish, 6-well plates, 24-well plates and 24-well transwell chambers with $8.0 \mu \mathrm{m}$ polycarbonated filters were purchased from Corning (NY, USA). Matrigel was purchased from Becton Dickinson and Company (Franklin, USA).

\section{Cell lines}

The human prostate carcinoma cell line (PC-3M) was obtained from American Type Culture Collection (Manassas, VA, USA). Human non-small-cell lung cancer cell line (A549) and Human umbilical vein endothelial cells (HUVECs) were obtained from Type Culture Collection of the Chinese Academy of Sciences, Shanghai, China. Luciferase-labeled A549 cells (A549-Luc cells) which were kindly provided by Caliper Life Sciences, Inc (Hopkinton, MA, USA) were cultured in Ham's F-12K (Kaighn's) medium supplemented with $10 \%$ fetal bovine serum. A549 cells and PC-3M cells were cultured in RPMI 1640 medium supplemented with $10 \%$ fetal bovine serum. HUVECs were cultured in ECM medium supplemented with $10 \%$ fetal bovine serum. In addition, $100 \mathrm{U} /$ $\mathrm{ml}$ streptomycin/penicillin was added to RPMI 1640 medium and ECM medium. All of the cells were cultured in incubator at $37^{\circ} \mathrm{C}, 5 \% \mathrm{CO}_{2}$. 


\section{Gal-3 small interfering RNA (siRNA) transfection}

A549 cells $\left(2 \times 10^{5}\right)$ seeded into six-well plates cultured to $60 \%$ confluence before transfection. Transfection with $8 \mu \mathrm{l}$ control, Gal-3, CD44 or N-cadherin siRNA duplex (25 $\mu \mathrm{mol} / \mathrm{l})$ was performed using $5 \mu \mathrm{l}$ Lipofectamine 2000 Reagent in $500 \mu \mathrm{l}$ Opti-MEM Culture Medium. After incubating $8 \mathrm{~h}$, change Opti-MEM Culture Medium to RPMI 1640 medium supplemented with $10 \%$ fetal bovine serum. Then cells were incubated at $37{ }^{\circ} \mathrm{C}$ for $24 \mathrm{~h}$. The efficiency of galectin-3 knockdown was assessed by western blot analysis of cellular lysates.

\section{Cancer cell-endothelial adhesion}

Cancer cell-endothelial adhesion was performed as previously described [11]. Tumor cells were cultured in 6-well plates and HUVECs was cultured in 24-well plates. Tumor cells treated with Gal-3, Gal-3 siRNA (siGal-3) transfection or ICG-001 ( $\beta$-catenin/TCF transcriptional inhibitor). After washed with PBS, tumor cells were released from the culture plates and labeled with $5 \mu \mathrm{mol} / \mathrm{l}$ DIO fluorescent cell labeling solution in serum-free RPMI 1640 medium for 30 $\min$ at $37^{\circ} \mathrm{C}$. After resuspension, $5 \times 10^{4}$ cells were applicated to the HUVECs monolayer cultured in 24-well plates for $1 \mathrm{~h}$ at $37^{\circ} \mathrm{C}$. Then the 24 -well plates were gently washed with PBS to remove free tumor cells and the fluorescently labeled cells remaining on the endothelial monolayer were counted in ten randomly selected fields of view using fluorescent microscope (NIKON Ti-U, Nikon, Japan) with a 10 objective (100 magnifications).

\section{Immunofluorescence staining}

A549 and PC-3M cells were seeded into 24-well plates (with coverslips inserted) at density of $5 \times 10^{4}$ cells per well. Gal-3 was added to PC-3M and A549 cells after overnight culture at $37^{\circ} \mathrm{C}$. The cells were fixed with icecold methanol/glacial acetic acid (3:1) for $10 \mathrm{~min}$ and blocked with $3 \%$ bovine serum albumin (BSA) in PBS for $20 \mathrm{~min}$ at room temperature. Then cells were incubated with a mouse anti-galectin-3 antibody (1:200) overnight at $4{ }^{\circ} \mathrm{C}$ and followed by reaction with FITC-conjugated secondary antibody (1:500) for $2 \mathrm{~h}$ at $37^{\circ} \mathrm{C}$. Finally, cells were stained with Hoechst 33342 to stain the nuclear, and fluorescence images were taken with fluorescence microscope (NIKON Ti-U, Nikon, Japan) with a 10 objective (150 magnifications).

\section{Wound scratch assay}

A549 cells were seeded into six-well plates and transfected with siRNA of Gal-3 or treated by ICG-001. The cell monolayer was scraped in a straight line with a p200 pipette tip and incubated under serum-free conditions. Photographs of the scratch were taken under an invert microscope at $0,12,24,36$, and $48 \mathrm{~h}$. Photographs at each time point were taken with Leica DFC420 camera. Gap width analysis was performed with scaleplate in microscope. Measurements were taken at multiple defined sites $(>6)$ along the scratch. Each scratch was given an average of all measurements. Data are derived from three independent experiments.

Formula:

$$
\begin{array}{r}
\text { Migration distance }=(\text { Gap width at } 0 \mathrm{~h} \\
- \text { Gap width at different time points }) / \text { Gap width at } 0 \mathrm{~h}
\end{array}
$$

\section{Cell invasion assay}

A549 cells were seeded into six-well plates and transfected with siRNA of Gal-3 or treated by ICG-001. The cells were released from the culture plates and suspended in medium without serum before application of $1 \times 10^{6}$ cells/well to the top side of the transwells. Medium with serum was added to the bottom chamber as a chemoattractant. After incubation at $37^{\circ} \mathrm{C}$ for $24 \mathrm{~h}$, cells remained in the top chambers (noninvasive) were removed together with the medium. The invaded cells in the bottom chamber were counted under a microscope with a 20 objective (200 magnifications).

\section{Western blot analysis}

A549 cells and PC-3M cells were lysed in a RIPA lysis buffer, cytoplasmic extraction reagent, and nucleus extraction reagent using Subcellular Structure Cytoplasmic and Nucleus Extraction Kit or membrane extraction reagent and cytoplasmic extraction using Membrane and Cytosol Protein Extraction Kit. Proteins were separated by $10 \%$ sodium dodecyl sulfate-polyacrylamide gel electrophoresis (SDSPAGE). After electrophoresis, the proteins were electrotransferred to PVDF membranes and then blocked with 5\% non-fat milk for $4 \mathrm{~h}$. The membranes were then incubated with a primary antibody against galectin- $3, \beta$-catenin, MMP2, MMP-9, CD44, N-cadherin, PCNA and $\beta$-actin at $4{ }^{\circ} \mathrm{C}$ for $12 \mathrm{~h}$. After three washes in TBST, the membranes were incubated with horseradish peroxidase-conjugated secondary antibody for $1 \mathrm{~h}$ at room temperature and were visualized by ECL reagent through Chemidoc XRS imaging system (BioRad, Hercules, California, USA).

\section{Quantitative real-time PCR}

Total RNA was extracted from the cell pellets using TRIzol Reagent following the manufacturer's 
instructions. The RNA concentration was measured by UV absorption at 260 and $280 \mathrm{~nm}$. The A260/A280 ratio was calculated to assess RNA quality and purity. Firststrand cDNA was produced from total RNA by using a qPCR RT Kit, according to manufacturer's instructions. Samples were cycled for $30 \mathrm{~s}$ at $95^{\circ} \mathrm{C}, 30 \mathrm{~s}$ at $59^{\circ} \mathrm{C}$ and $30 \mathrm{~s}$ for $72{ }^{\circ} \mathrm{C}$ for 40 cycles. QRT-PCR of the MUC1 mRNA and $\beta$-actin mRNA as internal control was performed on a LightCycler 480 II real-time PCR system (Roche, Basel, Switzerland), using the SYBR-Green Chemistry.

\section{Metastasis animal model and bioluminescent imaging}

Six-week-old female Balb/c athymic nude mice were maintained and used in accordance with the animal care protocol approved by Shandong University. Ten experimental animals were divided randomly into two groups.
Five animals/group were injected with A549-Luc cells which were transfected with siGal-3 or control siRNA via tail vein. The animals were maintained under standard conditions and observed daily. The mice were anesthetized and the fluorescence signal was monitored using the IVIS Kinetic in vivo imaging system (Caliper Life Sciences, Hopkinton, MA, USA) in 9 min after injecting Dluciferin potassium salt intraperitoneally every 10 days for up to 40 days. All mice were sacrificed and dissected for examining metastatic foci by light microscopy at day 40 .

\section{Statistical analysis}

All quantitative data are expressed as mean \pm SD. Statistical comparisons were performed by one-way analysis of variance. A $P$-value $<0.05$ was considered statistically significant. Statistical analysis was performed using SPSS/Win 13.0 software.
A

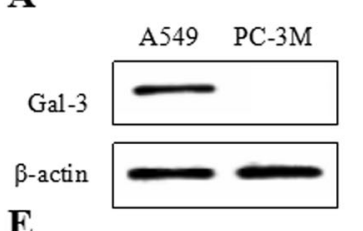

B

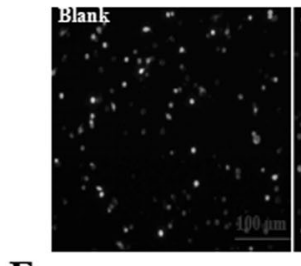

$\mathbf{F}$

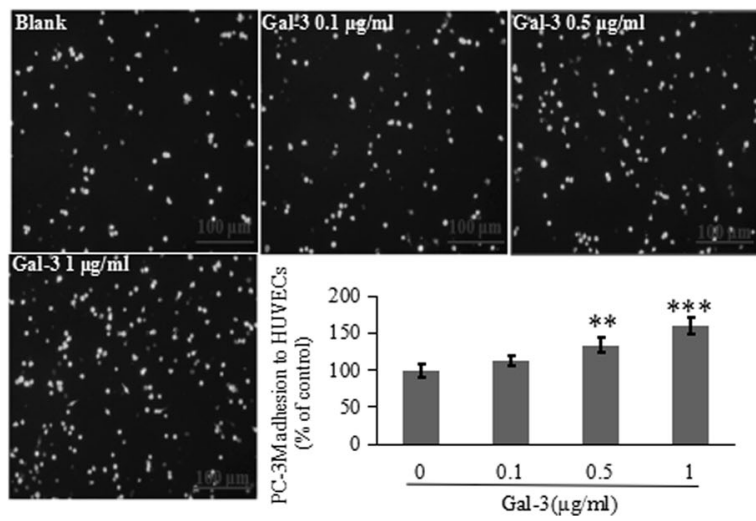

Fig. 1 Effects of intracellular and extracellular Gal-3 on tumor cell adhesion to HUVECs. Tumor cell adhesion to HUVEC monolayer was assessed using DIO fluorescent-labeled tumor cells. Expression of Ga1-3 (a) and MUC1 (b) in HT-29, A549, or PC-3M cells was determined by western blotting. c MUC1 mRNA levels in HT-29, A549, and PC-3M cells were determined by qRT-PCR. d Recombinant Gal-3 could not affect the expression of MUC1 in A549 and

\section{C}
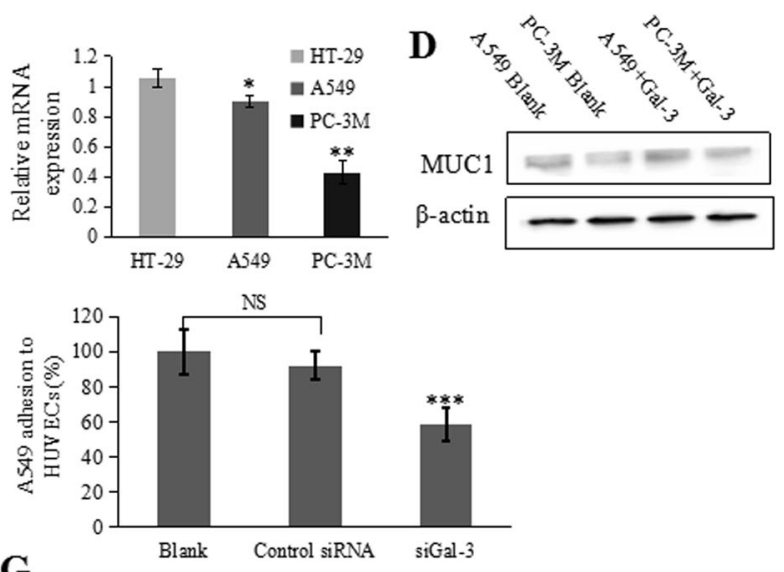

$\mathbf{G}$

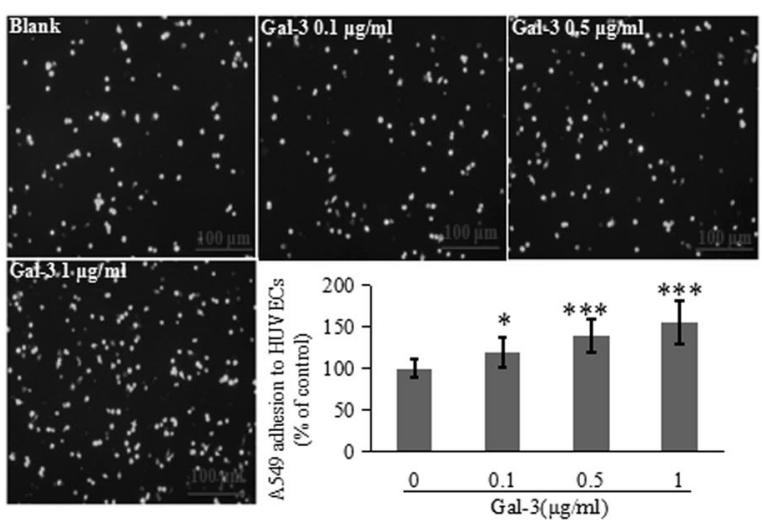

PC-3M cells. e siRNA Gal-3 suppression decreased A549 cell adhesion to HUVECs. The adhesion of PC-3M cells (f) or A549 cells (g) to HUVECs was determined after treatment of the cells with different concentration of recombinant Gal-3 for $8 \mathrm{~h}$. Data are presented as the means \pm SE from three separate experiments. ${ }^{*} P<0.05$, ${ }^{* *} P<0.01,{ }^{* * *} P<0.001$, NS not significant, when compared with blank group 

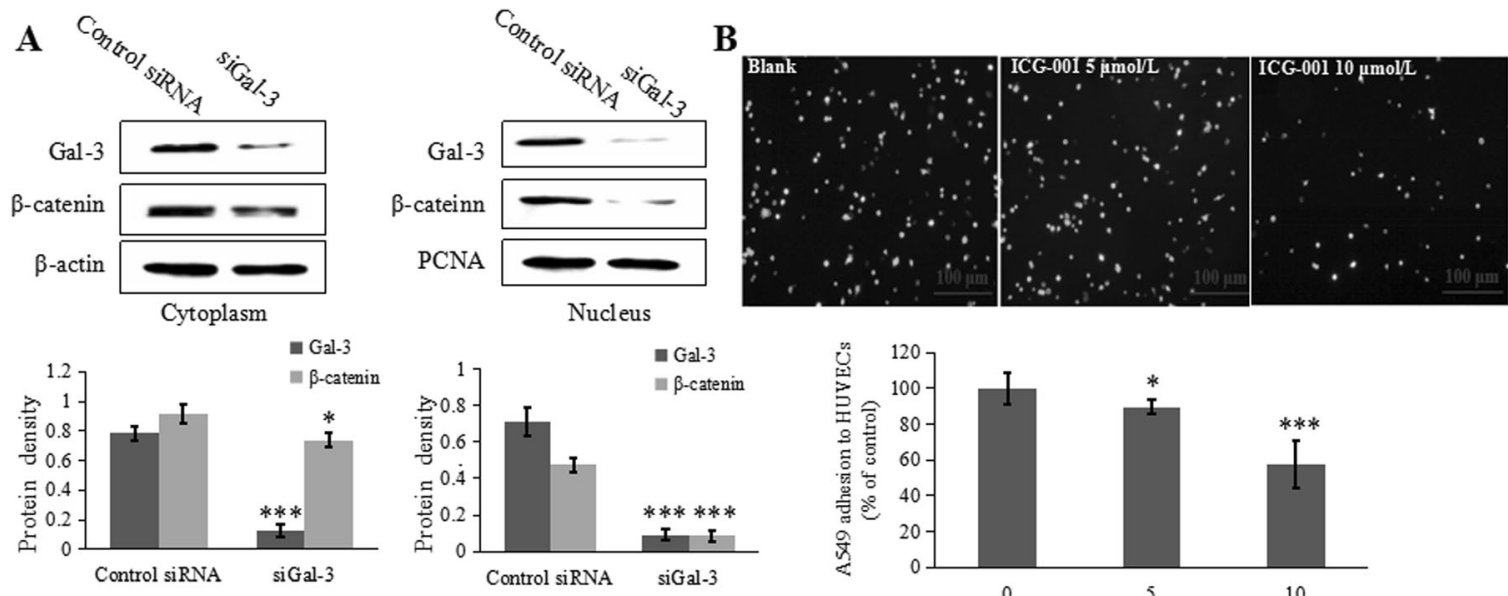

$\mathbf{C}$
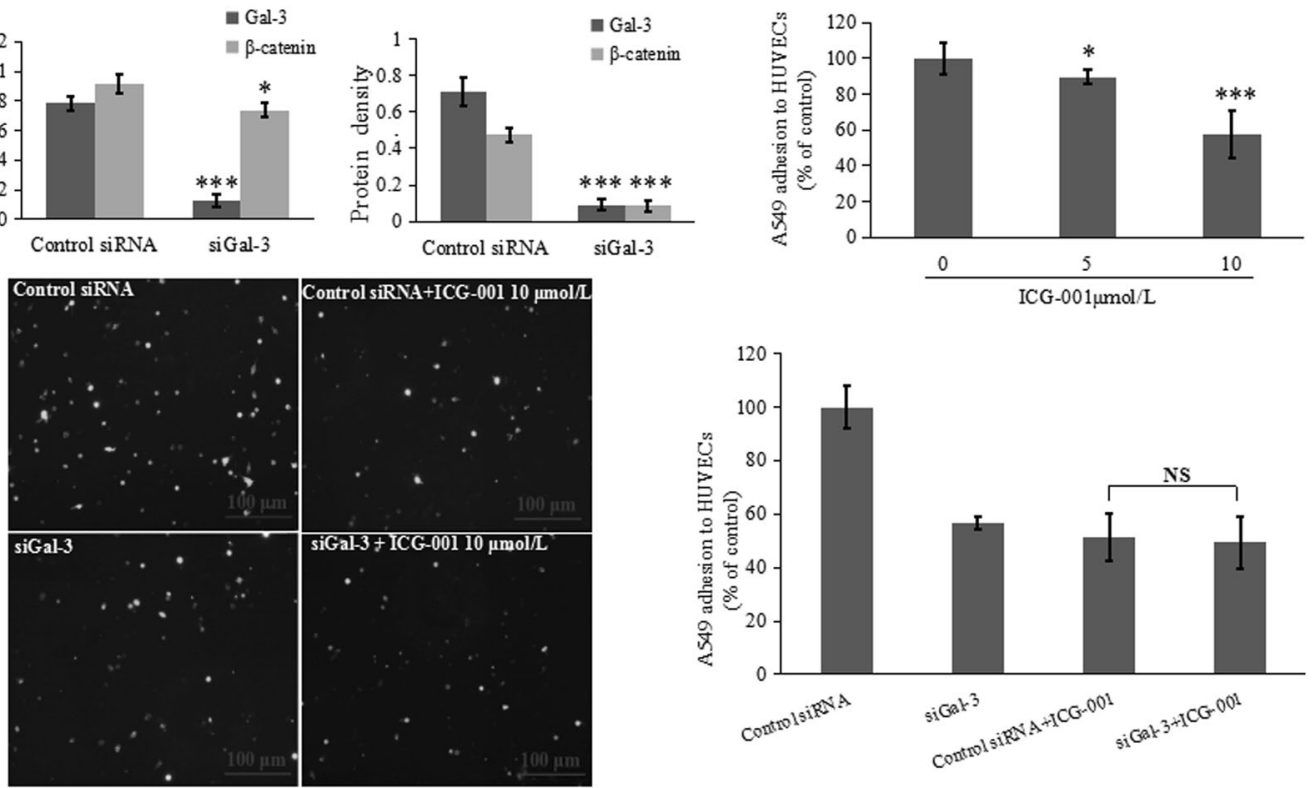

Fig. 2 Downregulation of Gal-3 expression decreased A549 cell adhesion to HUVECs through inhibition of nuclear accumulation of $\beta$ catenin. a Suppression of cell-associated Gal-3 significantly inhibited accumulation of $\beta$-catenin in nucleus. b ICG-001 decreased A549 cell

adhesion to HUVECs. c ICG-001 abolished inhibition of A549 cell adhesion to HUVECs induced by suppression of cell-associated Gal-3. Data are presented as the means $\pm \mathrm{SE}$ from three separate experiments. ${ }^{*} P<0.05,{ }^{* * *} P<0.001$, NS not significant, vs. blank group

\section{Results}

\section{Endogenous or exogenous Gal-3 increased A549 and PC-3M cell adhesion to HUVECs}

Two tumor cell lines, A549 cells which have high expression of endogenous Gal-3 [20] and PC-3M cells which has low expression of endogenous Gal-3 [21] were chosen to investigate the effects of endogenous or exogenous Gal-3 on tumor cell-HUVEC adhesion. The expression level of Gal-3 in A549 cells and PC-3M cells was confirmed and is shown in Fig. 1a. To determine the effect of endogenous Gal-3 on the adhesion of A549 cells to HUVECs, Gal-3 siRNA was used to downregulate the expression of Gal-3. A549 cells transfected with Gal-3 siRNA (siGal-3) showed significantly less adhesion (reduction rate of $41.2 \%, P<$ 0.01) to HUVECs compared with A549 cells treated with control siRNA (Fig. 1e).

It was reported previously that exogenous Gal-3 at concentrations similar to that seen in cancer patients promoted cancer cell adhesion to HUVECs by interaction

with MUC1 expressed on the membrane of cancer cells $[11,19]$. However, in the present study, we wanted to observe the effects of exogenous Gal-3 on the adhesion of HUVECs to cancer cells with low expression of MUC1. A549 and PC-3M cells were reported to have low MUC1 expression [22, 23], which was confirmed in Fig. 1B using HT-29 cells as positive control cell lines with high expression of MUC1. Moreover, MUC1 mRNA expression in A549 and PC-3M cells was also lower than that in HT-29 cells (Fig. 1c). In addition, recombinant Gal-3 did not affect the expression of MUC1 in these two cell lines (Fig. 1d). We examined the adhesion of A549 or PC-3M cells to HUVECs by incubation with different concentrations of recombinant Gal-3 for $8 \mathrm{~h}$. Results showed that $0.1,0.5,1 \mu \mathrm{g} / \mathrm{ml}$ Gal-3 significantly increased PC-3M cells' adhesion to HUVECs by $12.6 \%, 33.7 \%$, and $56 \%$, and increased A549 cell adhesion to HUVECs by $19.6 \%$, $39.4 \%$, and $55.1 \%$, compared with control cells (Fig. 1f, g). These results indicate that exogenous Gal-3 may promote tumor cell-HUVEC adhesion also through a MUC1-independent mechanism. 
Fig. 3 Downregulation of $\mathrm{N}-$ cadherin and CD44 expression induced by suppression of cellassociated Gal-3 was abolished by inhibition of $\beta$-catenin/TCF gene transcription. a The expression of $\mathrm{N}$-cadherin, CD44 in A549 cells was downregulated by siGal-3 treatment. b High expression of $\mathrm{N}$-cadherin showed in either HUVECs or A549 cells. c ICG001 decreased the expression of $\mathrm{N}$-cadherin but not CD44. d ICG-001 abolished the downregulation of $\mathrm{N}$-cadherin and CD44 induced by suppression of cell-associated Gal-3. Data are presented as the means \pm SE from three separate experiments. ${ }^{*} P<0.05,{ }^{* *} P<$ 0.01 , vs. control group
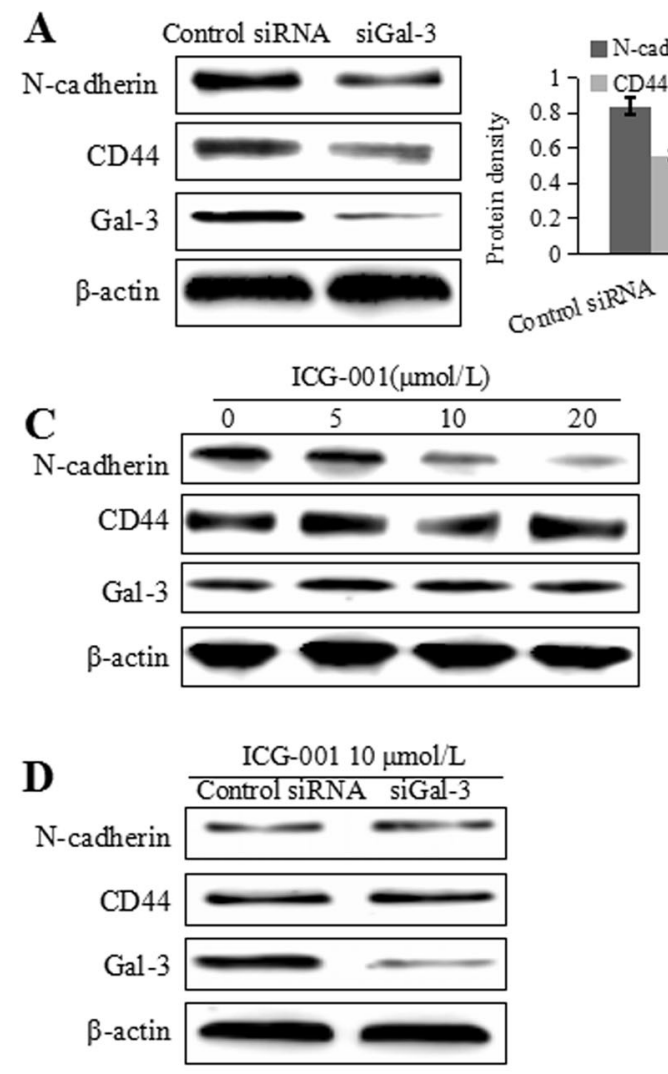

B

HUVEC PC-3M A549
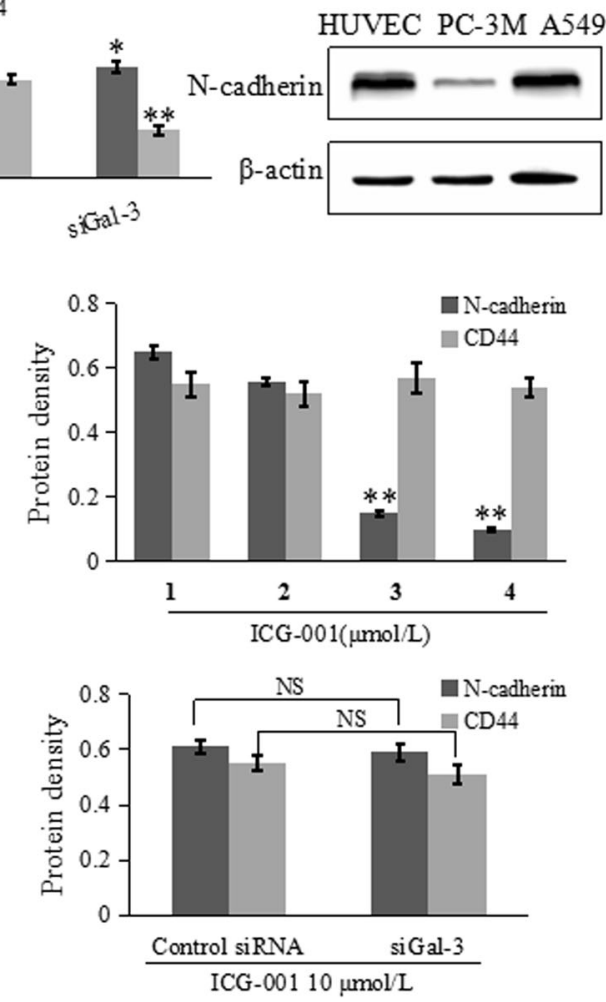

\section{Endogenous Gal-3 promoted A549 cell-HUVECs adhesion by upregulating CD44 and N-cadherin expression}

Previous studies showed that endogenous Gal-3 could bind to $\beta$-catenin and regulate accumulation of $\beta$-catenin in nucleus [8]. In this study, suppression of Gal-3 expression in A549 cells was shown to be associated with reduction of cell adhesion and decrease of the accumulation of $\beta$-catenin in nucleus (Fig. 2a).

To investigate whether $\beta$-catenin was involved in A549 cell adhesion to HUVECs, ICG-001, a small-molecule inhibitor to specially block $\beta$-catenin/TCF transcriptional activity [24], was introduced into the adhesion system. We found that pretreatment of A549 cells with 5 and $10 \mu \mathrm{mol} / 1$ ICG-001 resulted in reduction of A549 cell adhesion to HUVECs with reduction rate of $11.4 \%(P<0.05)$ and $42.1 \%(P<0.01)$, respectively, compared with untreated A549 cells (Fig. 2b).

To further determine whether the effect of endogenous Gal-3 on cancer cell-endothelial adhesion was involved in $\beta$-catenin/TCF transcriptional activity, A549 cells were incubated with ICG-001 after being transfected with control siRNA or siGal-3. As shown in Fig. 2c, in the presence of ICG-001 $(10 \mu \mathrm{mol} / \mathrm{l})$, control siRNA and siGal-3 treatment induced similar effect on reduction $(51.2 \%, P<0.01$ and
$49.3 \%, P<0.01)$ of A549 cell adhesion to HUVECs compared to blank control group. These data indicate that the involvement of endogenous Gal-3 in the adhesion of A549 cells to HUVECs was depending on $\beta$-catenin/TCF transcriptional activity.

Because multiple CAMs are involved in mediating cancer cell-endothelial adhesion and CD44 is regulated by $\beta$ catenin [25], we speculated that endogenous Gal-3 might promote A549 cell adhesion to HUVECs through regulation of the expression of $\mathrm{N}$-cadherin and $\mathrm{CD} 44$ via $\beta$-catenin/ TCF. High expression of N-cadherin was detected in both HUVECs and A549 cells (Fig. 3b), which suggests that Ncadherin might be a key CAM involving in A549 cellHUVEC adhesion. As shown in Fig. 3a, suppression of cell Gal-3 expression inhibited the expression of $\mathrm{N}$-cadherin and CD44 in A549 cells. After treatment with ICG-001 ( $\beta$ catenin/TCF transcriptional inhibitor), the expression of $\mathrm{N}$ cadherin in A549 cells was decreased in a concentrationdependent manner, while the expression of CD44 showed no significant change which suggested that CD44 is also regulated by other ways (Fig. 3c). However, in the presence of $10 \mu \mathrm{mol} / 1$ ICG-001, Gal-3 suppression did not decrease the expression of $\mathrm{N}$-cadherin and CD44 (Fig. 3d). These results indicate that the decreased expression of $\mathrm{N}$-cadherin and CD44 induced by Gal-3 suppression were dependent on the presence of $\beta$-catenin. 


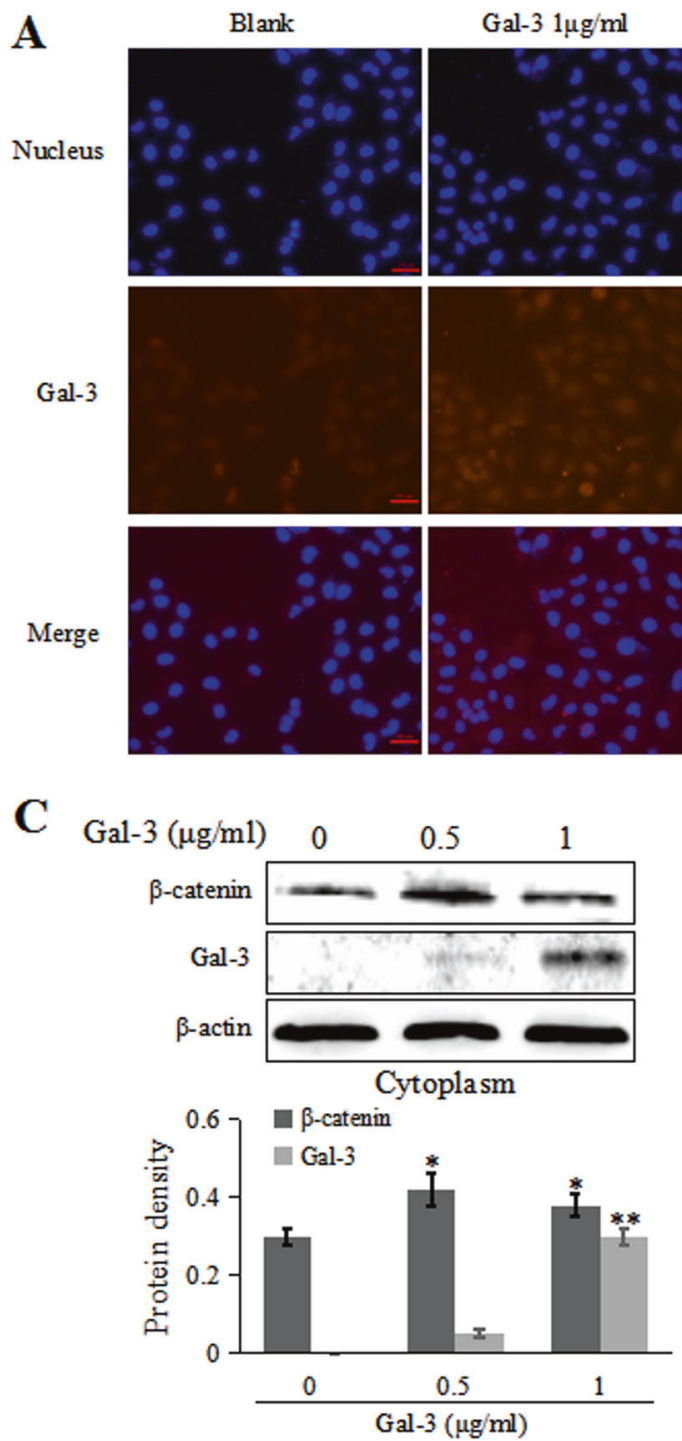

Fig. 4 Exogenous Gal-3 increased nuclear accumulation of $\beta$-catenin via internalization in PC-3M cells. a PC-3M cells were treated with 1 $\mu \mathrm{g} / \mathrm{ml} \mathrm{Gal-3}$ for $2 \mathrm{~h}$. Gal-3 was visualized with an anti-galectin-3 antibody (red), and the cell nucleus was visualized with Hoechst 33342 (blue). b The expression of Gal-3, N-cadherin and CD44 in PC$3 \mathrm{M}$ cells after incubation with $0.5 \mu \mathrm{g} / \mathrm{ml}$ recombinant Gal-3 at different time points was assessed by western blotting. c After treatment with $0.5,1 \mu \mathrm{g} / \mathrm{ml} \mathrm{Gal}-3$ for $8 \mathrm{~h}$, the expression of Gal-3 and $\beta$-catenin in

\section{Recombinant Gal-3 promoted tumor cell adhesion to HUVECs by entering cells and upregulating $\beta$ - catenin expression and nuclear accumulation}

We next explored the mechanism of exogenous Gal-3 on MUC1-independent cancer cell adhesion to HUVECs. It has been reported that exogenous Gal-3 had the ability to enter macrophages via endocytosis [26]. Thus, we speculated that introduction of recombinant Gal-3 to the cells could get into the cells and regulate adhesion of A549 or PC-3M cells (with low MUC1 expression) to HUVECs in a similar
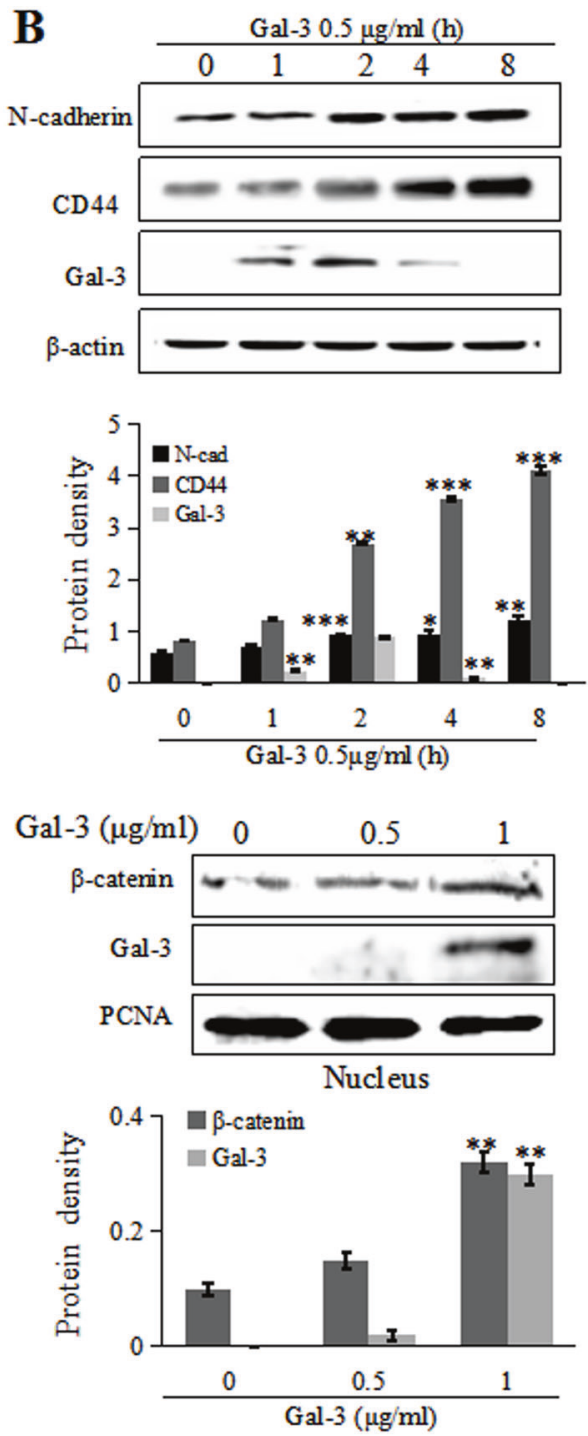

cytoplasm and nucleus of PC-3M cells was assessed using a Subcellular Structure of Cytoplasm and Cell Nucleus Extraction Kit and western blotting. The band densities were quantified by Chemidoc XRS imaging system (Bio-Rad, Hercules, CA, USA) and were normalized to $\beta$-actin. Data are presented as the means \pm SE from three separate experiments. ${ }^{*} P<0.05,{ }^{* *} P<0.01,{ }^{* * *} P<0.001$, vs. control group

manner as intracellular Gal-3. First, recombinant Gal-3 showed the ability to enter into PC-3M cells, which do not express Gal-3 (Fig. 4a). After incubation with recombinant Gal-3, the expression of Gal-3 in PC-3M cells was rapidly increased in a time-dependent manner for $2 \mathrm{~h}$, and then decreased gradually over $8 \mathrm{~h}$. After incubation of PC-3M cells with $0.5,1 \mu \mathrm{g} / \mathrm{ml}$ recombinant Gal-3 for $8 \mathrm{~h}, \mathrm{Gal}-3$ entered into both cytoplasm and nucleus in dose-dependent manner (Fig. 4b, c). Recombinant Gal-3 also showed ability to enter into A549 cells (with high expression of endogenous Gal-3) after downregulating the expression of Gal-3 by 


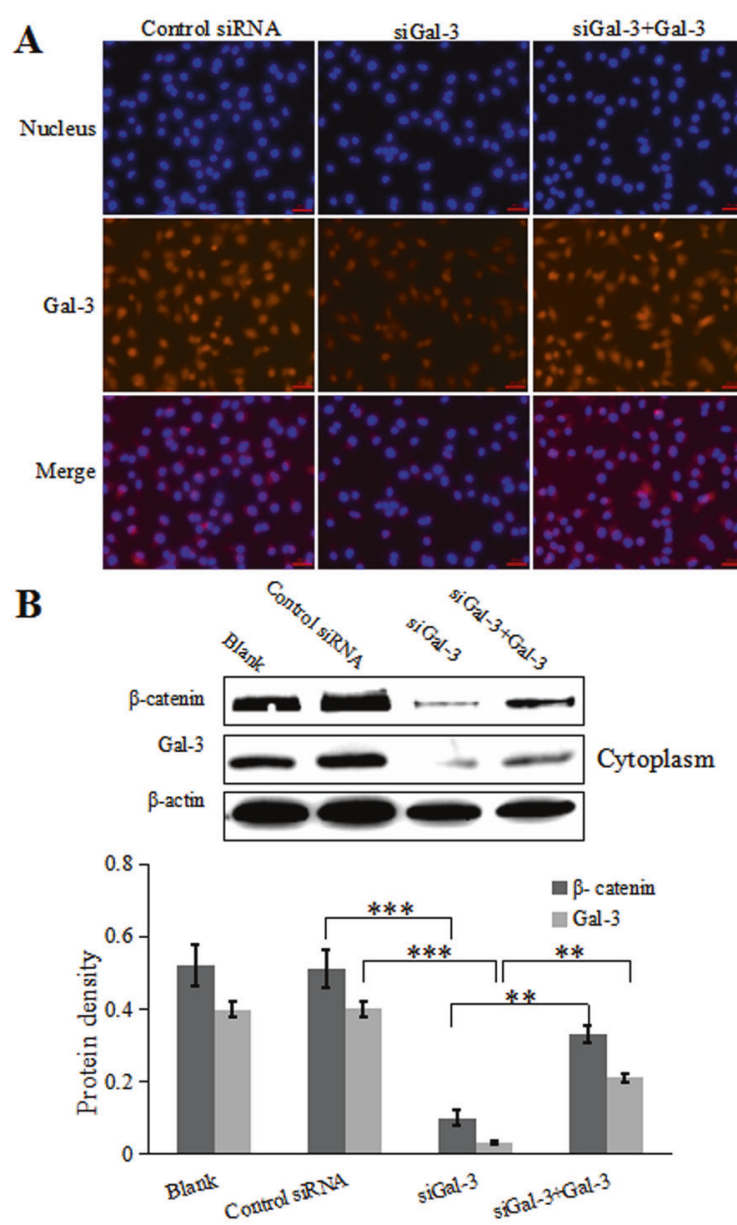

Fig. 5 Exogenous Gal-3 increased nuclear accumulation of $\beta$-catenin via internalization in A549 cells. a A549 cells were treated with $1 \mu \mathrm{g} /$ $\mathrm{ml} \mathrm{Gal}-3$ for $2 \mathrm{~h}$. Gal-3 was visualized with an anti-galectin-3 antiboby (red), and the cell nucleus was visualized with Hoechst 33342 (blue). b After siRNA suppression of Gal-3, A549 cells were incubated with or without $1 \mu \mathrm{g} / \mathrm{ml} \mathrm{Gal-3}$ for $8 \mathrm{~h}$, and the expression of gal-3 and $\beta$ catenin in cytoplasm and nucleus of A549 cells was assessed by Subcellular Structure of Cytoplasm and Cell Nucleus Extraction Kit

RNA interference (siGal-3) (Fig. 5a). Results showed that Gal-3 could be seen in both cytoplasm and nucleus of A549 cells in endogenous Gal-3 knockdown cells (Fig. 5b). In order to rule out cell membrane contamination of Gal-3 expression in cytoplasm, we separated the cell membrane and cytoplasm using Membrane and Cytosol Protein Extraction Kit. The result showed the expression of Gal-3 in cytoplasm was significantly increased after incubation of PC-3M and A549 cells with $1 \mu \mathrm{g} / \mathrm{ml}$ recombinant Gal-3 for $2 \mathrm{~h}$ (Fig. 5c). Therefore, the present data confirmed that exogenous recombinant Gal-3 had the ability to enter the cytoplasm and nucleus of tumor cells that contain low levels of endogenous Gal-3. Simultaneously, the entrance of Gal-3 in PC-3M cells was accompanied by increased expression of $\beta$-catenin in nucleus (Fig. 4c). Moreover, the expression of
C

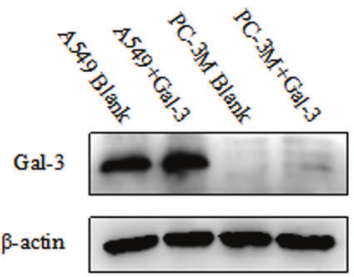

: 0.8 Cytoplasm

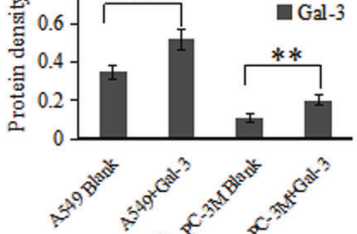

$\mathrm{Na}^{+}, \mathrm{K}^{+}$-ATPase

Gal-3
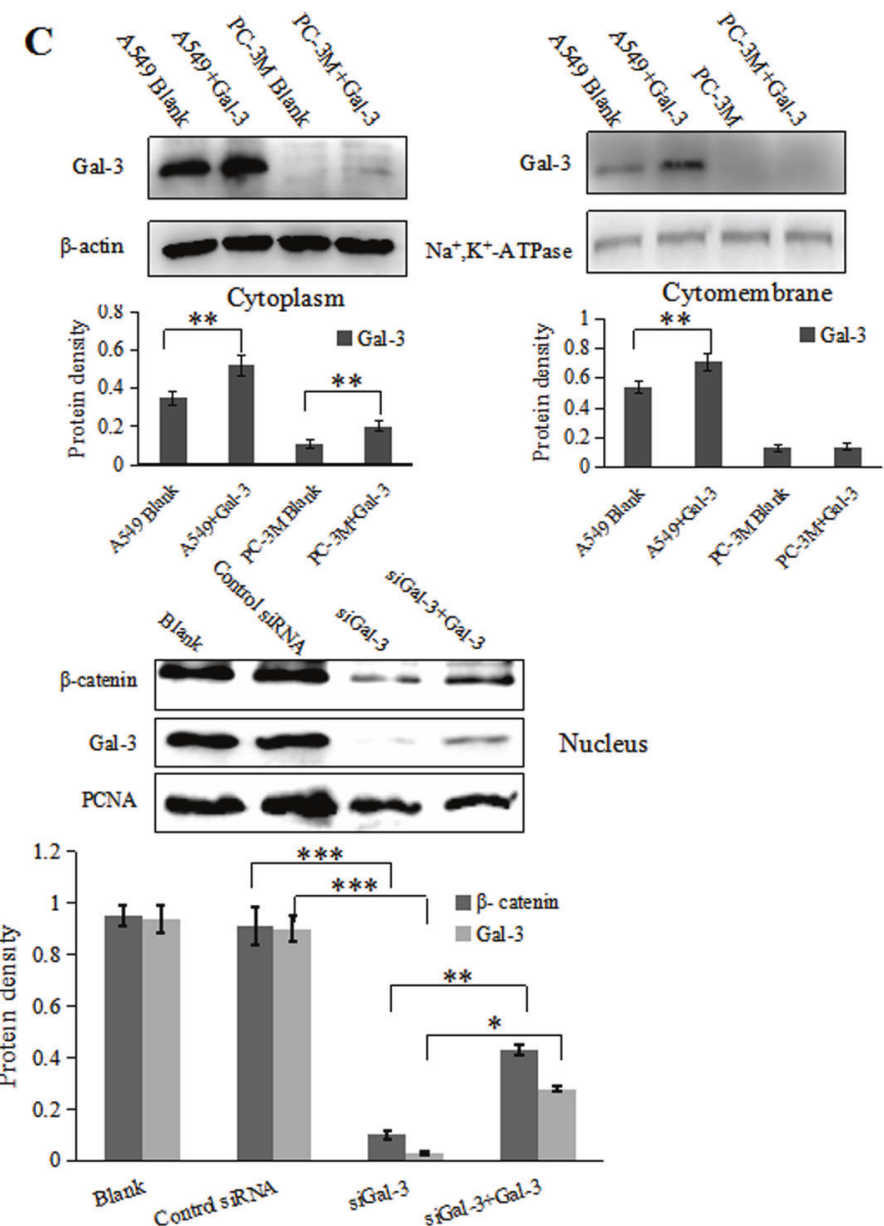

and western blotting. c After treatment with $1 \mu \mathrm{g} / \mathrm{ml} \mathrm{Gal}-3$ for $2 \mathrm{~h}$, the expression of Gal-3 in cytoplasm and cytomembrane of A549 and PC$3 \mathrm{M}$ cells was assessed by Membrane and Cytosol Protein Extraction Kit and western blotting. The band densities were quantified by Chemidoc XRS imaging system (Bio-Rad, Hercules, CA, USA) and were normalized to $\beta$-actin. Data are presented as the means $\pm \mathrm{SE}$ from three separate experiments. ${ }^{*} P<0.05,{ }^{* *} P<0.01$, ${ }^{* * *} P<0.001$, vs. control group

$\beta$-catenin in both cytoplasm and nucleus in A549 cells transfected with siGal-3 also decreased, while it was increased in the presence of recombinant Gal-3 (Fig. 5b).

After being transfected with siGal-3, the adhesion of A549 cells to HUVECs was significantly increased by introduction of $1 \mu \mathrm{g} / \mathrm{ml}$ recombinant Gal-3 for $8 \mathrm{~h}$ (Fig. 6a). But this effect did not occur in the presence of $10 \mu \mathrm{mol} / \mathrm{IICG}-001$ (Fig. 6b). Similarly, the presence of $10 \mu \mathrm{mol} / \mathrm{l}$ ICG-001 reduced recombinant Gal-3 $(1 \mu \mathrm{g} / \mathrm{ml}$, $8 \mathrm{~h}$ )-mediated increase of PC-3M cell adhesion to HUVECs (Fig. 6c).

Taken together, these results indicate that exogenous Gal-3 could promote the adhesion to HUVECs of tumor cells with low MUC1 expression by upregulating $\beta$-catenin and its nuclear translocation. 


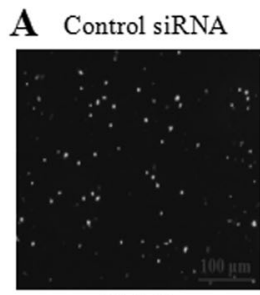

siGal-3
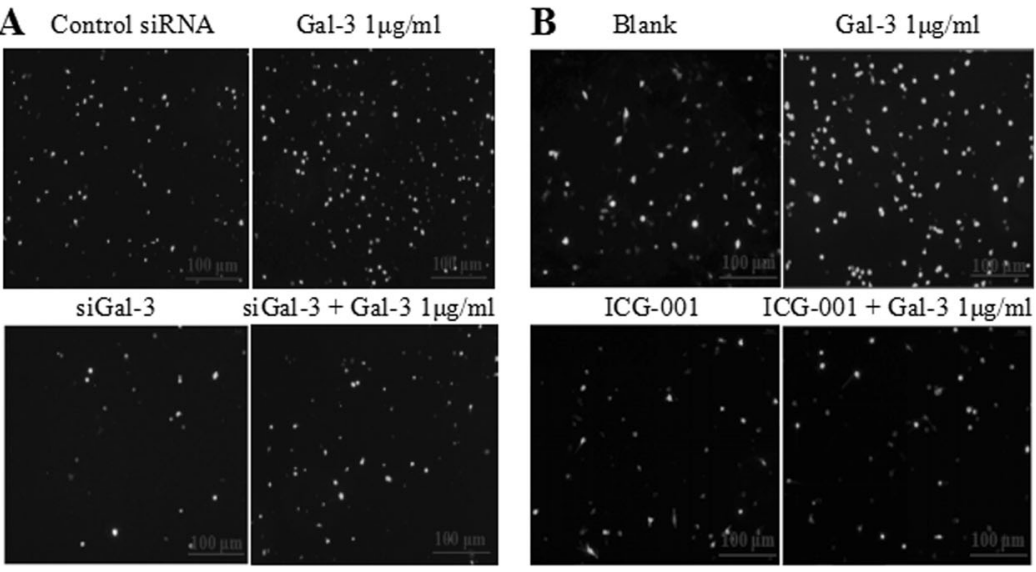

ICG-001
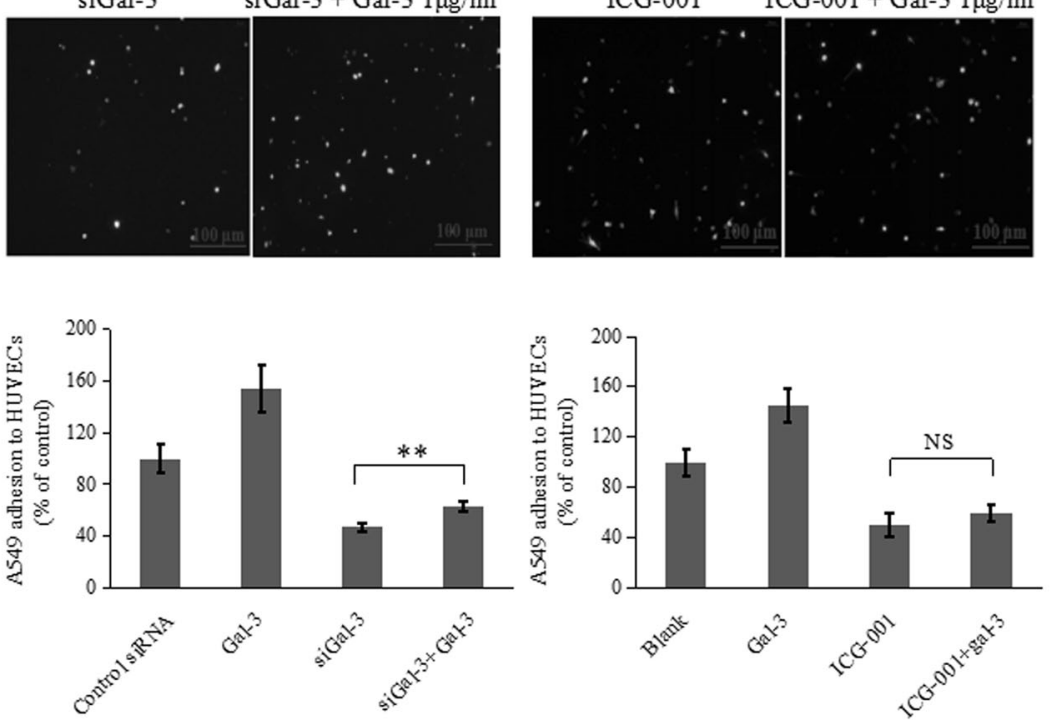

Fig. 6 Effect of exogenous Gal-3 on A549 cell adhesion to HUVECs was affected by siGal-3 and ICG-001. a Exogenous Gal-3 increases adhesion of A549 cells which were transfected with siGal-3. b The increase of Gal-3-mediated A549 cell adhesion to HUVECs was significantly inhibited by the presence of ICG-001. $\mathbf{c}$ The increase of Gal-

\section{$\mathrm{N}$-cadherin and CD44 were involved in promoting tumor cell adhesion to HUVECs induced by exogenous Gal-3}

After treatment of PC-3M cells with $1 \mu \mathrm{g} / \mathrm{ml}$ recombinant Gal-3 for $0,1,2,4$, and $8 \mathrm{~h}$, the expression of $\mathrm{N}$-cadherin and $\mathrm{CD} 44$ in $\mathrm{PC}-3 \mathrm{M}$ cells showed a time-dependent increase (Fig. 4b). After treatment with $0.5,1 \mu \mathrm{g} / \mathrm{ml}$ recombinant Gal-3 for $8 \mathrm{~h}$, the expression of $\mathrm{N}$-cadherin and CD44 in PC-3M cells or A549 cells was significantly increased (Fig. 7a, b). Moreover, after A549 cells transfected with Gal-3 siRNA, the endogenous expression of Ncadherin and CD44 decreased in comparison with that in control siRNA cells, while increased after incubation with recombinant Gal-3 for $8 \mathrm{~h}$ (Fig. 7c). To further investigate the relationship between increased expression of $\mathrm{N}$-cadherin and CD44 induced by recombinant Gal-3 and $\beta$-catenin, 10 $\mu \mathrm{mol} / \mathrm{ICG}-001$ was used to inhibit the $\beta$-catenin/TCF transcriptional activity.

However, when A549 cells were exposed to $10 \mu \mathrm{mol} / \mathrm{l}$ ICG-001, the expression of N-cadherin significantly decreased while the expression of CD44 has no markedly
$\mathrm{Gal}-31 \mu \mathrm{g} / \mathrm{ml}$
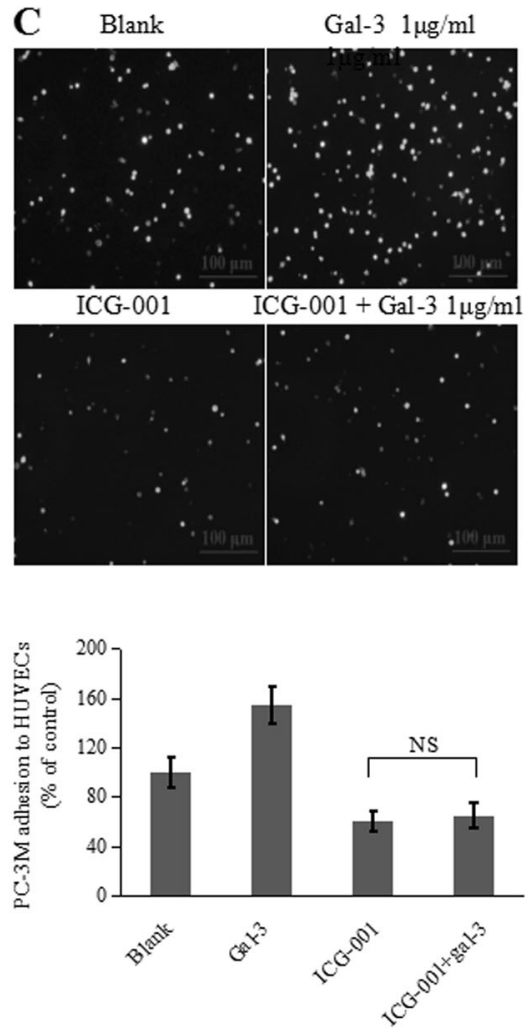

3-mediated PC-3M cell adhesion to HUVECs was significantly inhibited by the presence of ICG-001. Data are presented as the means \pm SE from three separate experiments. ${ }^{* *} P<0.01,{ }^{* * *} P<0.001$, NS not significant

difference. And recombination Gal-3 did not alter the expression of these two CAMs in the presence of ICG-001 (Fig. 7d). These results suggest that exogenous Gal-3 could upregulate the expression of N-cadherin and CD44 in both A549 cells and PC-3M cells in the presence of $\beta$-catenin.

To gain further insight into the role of $\mathrm{N}$-cadherin and CD44 in regulating adhesion of tumor cells to HUVECs, siRNA to N-cadherin or CD44 in A549 cells was conducted before performance of cell adhesion to HUVECs. It was found that suppression of N-cadherin or CD44 by RNA interference resulted in reduction of adhesion of A549 cells to HUVECs. After treatment with $1 \mu \mathrm{g} / \mathrm{ml}$ recombinant Gal3 for $8 \mathrm{~h}$, adhesion of A549 cells transfected with siCD44 or siN-cadherin to HUVECs was significantly increased, accompanying with an increase of CD44 and N-cadherin expression (Fig. 8a-c). Interestingly, suppression of $\mathrm{N}$ cadherin expression further induced reduction of A549 cell adhesion to HUVECs (53.7\%) than suppression of CD44 expression (36.3\%). These results indicate that $\mathrm{N}$-cadherin and CD44 may both play an essential role in Gal-3mediated tumor cell-HUVEC adhesion, but $\mathrm{N}$-cadherin may make more contribution than CD44. 

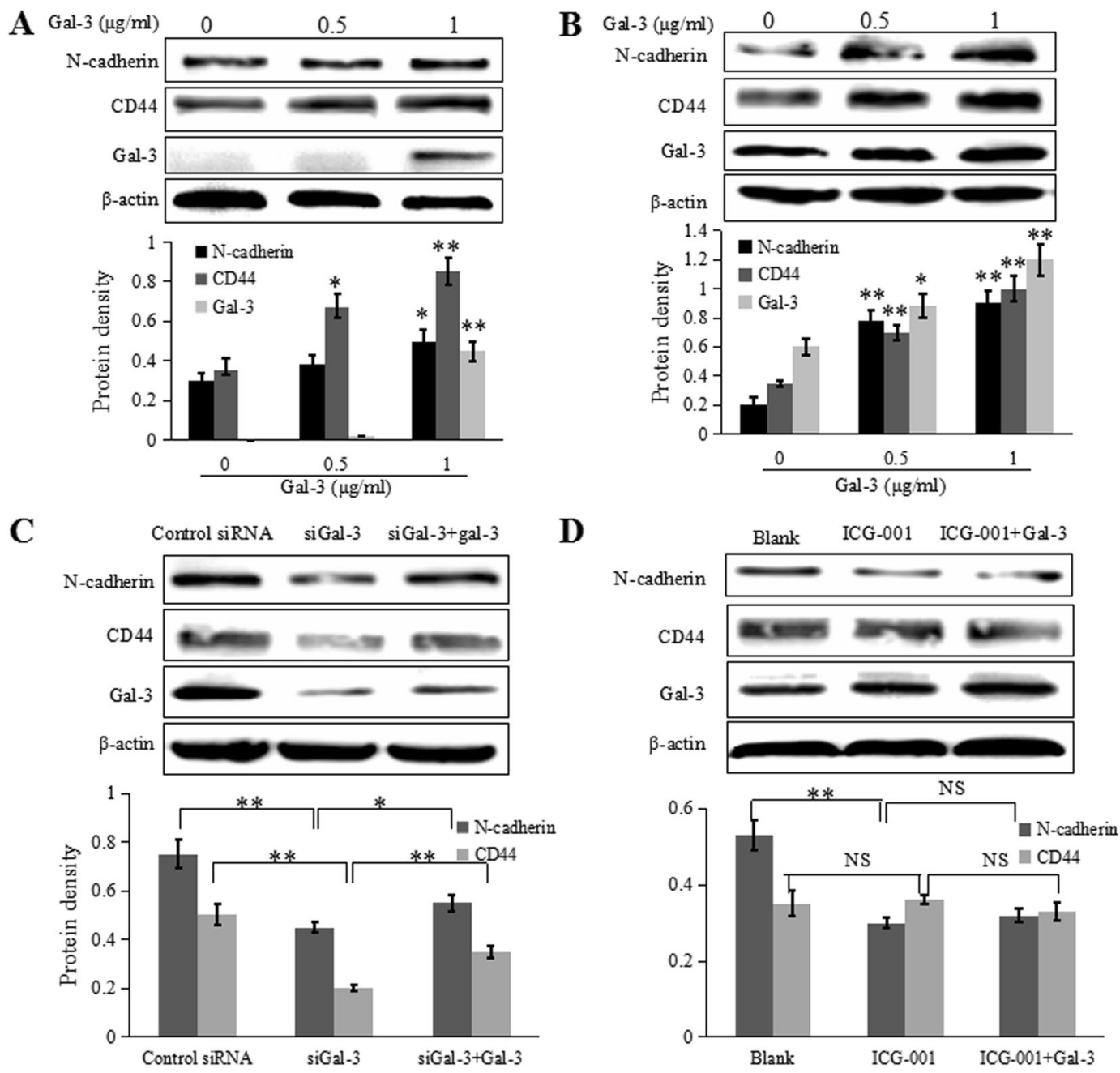

Fig. 7 Exogenous Gal-3 increased the expression of N-cadherin and CD44 in PC-3M and A549 cells by internalization. a, b After $8 \mathrm{~h}$ treatment of the cells with recombination Gal-3 $(0.5,1 \mu \mathrm{g} / \mathrm{ml})$ expression of N-cadherin and CD44 in PC-3M cells (a) and A549 cells (b) were both increased. c, $\mathbf{d}$ The expression of N-cadherin, CD44 and Gal-3 was assessed after incubation of the Gal-3-suppressed A549

\section{Endogenous Gal-3 promoted migration and invasion of A549 cells and was dependent on $\beta$ - catenin/TCF transcriptional activity}

In the wound scratch assays, suppression of Gal-3 expression by RNA interference in A549 cells resulted in slower closure of the gaps than the untreated cells or control siRNA cells for $0,12,24,36$, and $48 \mathrm{~h}$. In the presence of $10 \mu \mathrm{mol} / \mathrm{l}$ ICG-001, the A549 cell migration was significantly inhibited at 24,36 , and $48 \mathrm{~h}$ in comparison to untreated cells. Moreover, the presence of siGal-3 and ICG-001 almost completely abolished A549 cell migration (Fig. 9a).

In the invasion assay, the number of invasive A549 cells through Matrigel was decreased significantly by cells with or without $1 \mu \mathrm{g} / \mathrm{ml} \mathrm{Gal}-3$ for $8 \mathrm{~h}$ (c) or in the presence of 10 $\mu \mathrm{mol} / \mathrm{l}$ ICG-001 (d). The band densities of these proteins were quantified by Chemidoc XRS imaging system (Bio-Rad, Hercules, CA, USA) and normalized to $\beta$-actin. Data are presented as the means \pm SE from three separate experiments. ${ }^{*} P<0.05,{ }^{* *} P<0.01$, vs. control group. NS not significant

suppression of Gal-3 expression or $10 \mu \mathrm{mol} / \mathrm{l}$ ICG-001 compared to control siRNA or blank group. Co-presence of siGal-3 and ICG-001 dramatically inhibited the invasion of A549 cells (Fig. 9b). Moreover, we also observed that suppression of Gal-3 expression decreased the expression of $\beta$-catenin in both cytoplasm and nucleus (Fig. 5b). These results indicate that endogenous Gal-3 promotes the expression of $\beta$-catenin in cytoplasm and its nucleus accumulation, which may play a crucial role in A549 cells migration and invasion. Moreover, the expression of MMP2 and MMP-9 in A549 cells was inhibited by the presence of ICG-001 in a concentration-dependent manner, indicating that both MMP-2 and MMP-9 may contribute to the migration and invasion ability of A549 cells induced by Gal-3/ $\beta$-catenin pathway (Fig. 9c). 
A

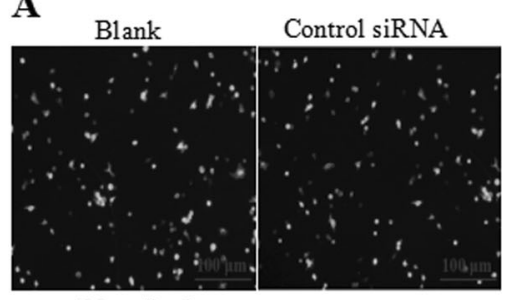

siN-cadherin

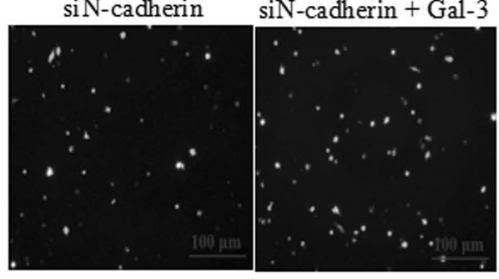

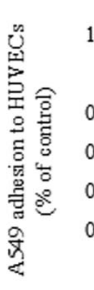

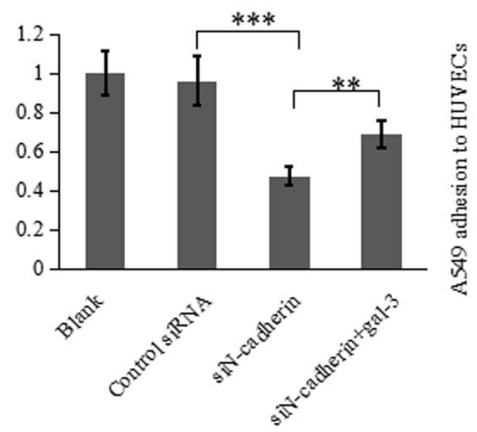

Fig. 8 Exogenous Gal-3 promoted tumor cell-HUVEC adhesion by upregulation of expression of $\mathrm{N}$-cadherin and CD44 in cells of $\mathrm{N}$ cadherin and CD44 suppression. a, b The effect of exogenous Gal-3 on A549 cell adhesion to HUVECs after siRNA suppression of $\mathrm{N}$ cadherin (a) and CD44 (b). c A549 cells were treated with $1 \mu \mathrm{g} / \mathrm{ml}$
B

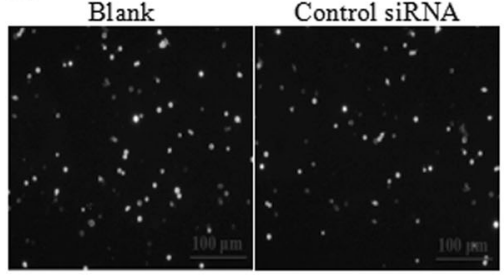

$\operatorname{siCD} 44$
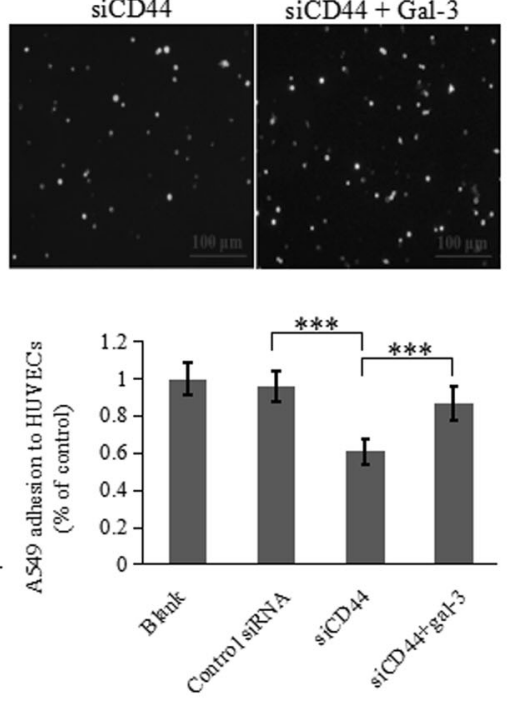

C
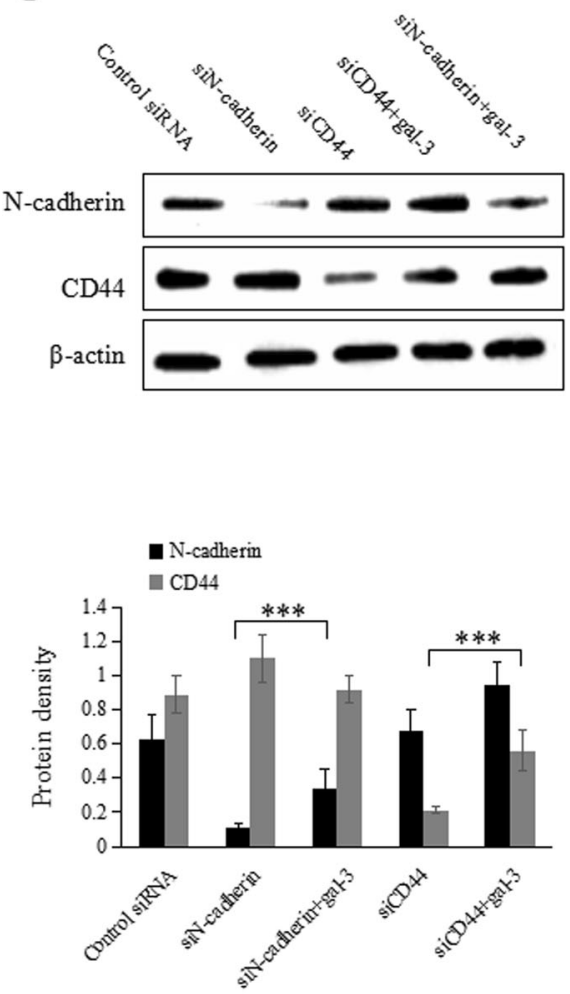

recombinant Gal-3 for $8 \mathrm{~h}$ after transfection of the cells with $\mathrm{N}$ cadherin siRNA or CD44 siRNA. The expression of $\mathrm{N}$-cadherin and CD44 were determined by western blotting. Data are presented as the means \pm SE from three separate experiments. ${ }^{*} P<0.05,{ }^{* *} P<0.01$

\section{Downregulation of galectin-3 expression inhibited the metastasis of A549 cells in vivo}

To explore the effects of Gal-3 in tumor metastasis in vivo, 10 nude mice were injected with A549-Luc cells which were transfected with siGal-3 or control siRNA via tail vein. Lung metastasis in this model was determined using in vivo imaging at different time points. At day 10, obvious metastatic foci in the lungs appeared in all mice injected with A459-Luc cells, while weak foci showed in only one mouse injected with A549-Luc cells transfected with siGal-3 (Fig. 10a). At either day 20 or day 40, the luminescence intensity of metastatic foci in the lungs in mice injected with A459-Luc cells transfected with siGal3 was significantly lower than in mice injected with A549Luc cells (Fig. 10b, c). The macroscopic appearance of lungs at $40 \mathrm{~d}$ in two mice groups was consistent with luminescence intensity (Fig. 10d). These results indicate that pretreatment of A549 cells with siGal-3 transfection resulted in an obvious inhibition on the pulmonary metastasis of A549 cells.

\section{Discussion}

Gal-3 is an extra- and intra-cellular $\beta$-galactoside-binding protein, and is widely expressed in various tissues. Gal-3 interacts with glycoproteins expressed on cell surface through its carbohydrate recognition domain. Gal-3 binds to $\beta$-galactosides present in N-glycans and O-glycans [27]. Thus, Gal-3 interacts with the glycoprotein MUC1 and EGFR, then regulated MUC1 and EGFR cellular distribution and activated EGFR downstream pathways in pancreatic cancer cells [28]. Exogenous Gal-3 was shown to promote tumor cell homotypic aggregation and adhesion to HUVECs and increase EGFR dimerization and activation [29] by interaction with O-linked glycans on MUC1 [12, $19,30]$. In this study, exogenous and endogenous galectin-3 regulated adhesion of tumor cells through MUC1independent mechanisms.

We found that suppression of endogenous Gal-3 by siGal-3 in A549 cells decreased cell adhesion to HUVECs, an effect that is associated with downregulation of the expression of $\beta$-catenin and two CAMs, N-cadherin and 

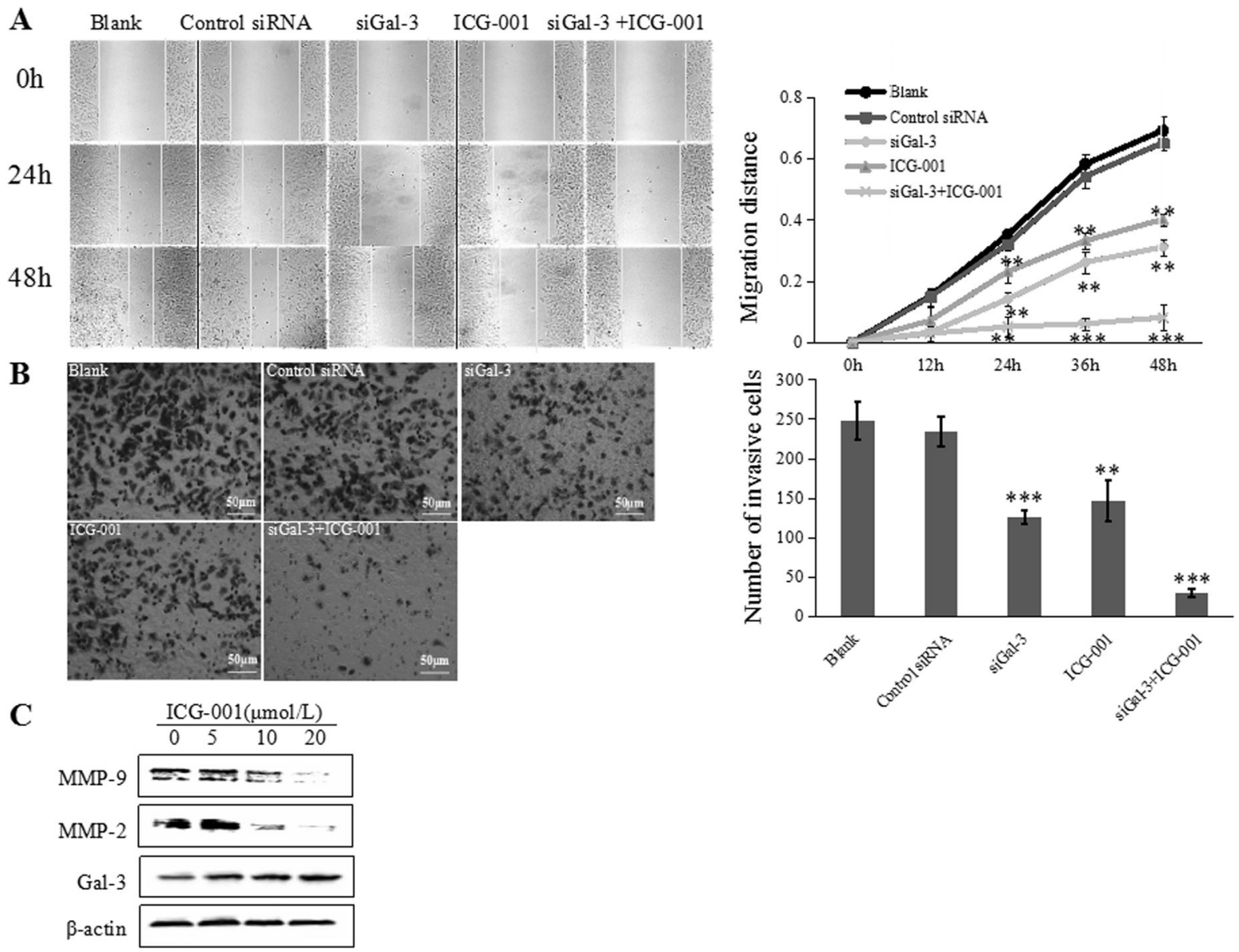

Fig. 9 Effect of cell-associated Gal-3 on the migration and invasion of A549 cells. Effects of cell-associated Gal-3 on the migration and invasion of A549 cells in the presence or absence of $10 \mu \mathrm{mol} / \mathrm{l} \mathrm{ICG-}$ 001 were determined using wound scratch assay (a) or transwell

CD44. Adhesion of A549 cells to HUVECs was seen to be significantly decreased, and the expression of $\mathrm{N}$-cadherin was decreased while the expression of CD44 was not affected in the presence of $\beta$-catenin/TCF-mediated transcription inhibitor ICG-001. This indicates that $\beta$-catenin/ TCF-mediated transcriptional activity was closely associated with A549 cell adhesion to HUVECs and the expression of N-cadherin. The presence of ICG-001 showed to abolish Gal-3-mediated increase of A549 adhesion to HUVEC. We therefore deduce that endogenous Gal-3 promotes A549 cell adhesion to HUVECs through upregulation of $\mathrm{N}$-cadherin and CD44 via $\beta$-catenin/TCF transcription.

The Wnt/ $\beta$-catenin signaling pathway plays an essential role in homeostasis, organogenesis and cancer progression. In the absence of Wnt stimuli, $\beta$-catenin is degraded by the complex that contains axin, adenomatous polyposis coli (APC) and glycogen synthase kinase $3 \beta$ (GSK-3 $\beta$ ). Aberrant activation of the $\mathrm{Wnt} / \beta$-catenin pathway can increase

invasion assay (b). c Effects of ICG-001 on the expression of MMP-2 and MMP-9 were evaluated by western blotting. Data are presented as the means $\pm \mathrm{SE}$ from three separate experiments. ${ }^{* * *} P<0.01,{ }^{* * * *} P<$ 0.001 , vs. control siRNA

$\beta$-catenin accumulation in nucleus, leading to activation of the transcription of Wnt-target genes including cyclin D1, c-Myc [31]. The expression of $\mathrm{N}$-cadherin was upregulated in many tumors, such as prostate cancer, breast cancer, gastric cancer, colon cancer, pancreatic cancer, esophagus cancer, and melanoma cancer [32-38]. In addition, expression of N-cadherin enhances the movement of HCT-8/E11 colon cancer cells $[39,40]$ and was involved in stromalmesenchymal cell adhesion [41]. In the present study, the high expression of N-cadherin in HUVECs and A549 cells demonstrated that $\mathrm{N}$-cadherin might be a key CAM to mediate the adhesion of these two cells. $\mathrm{N}$-cadherin also showed to increase breast cancer adhesion to endothelial cells and enhance tumor cell ability to enter and exit the blood vessel [42]. N-cadherin was also reported to increase the expression of MMP-9 by activating MEK/MAPK pathway, eventually promote cancer metastasis and invasion [43]. It was previously reported that $\mathrm{N}$-cadherin was upregulated in epithelial-mesenchymal transition (EMT) 

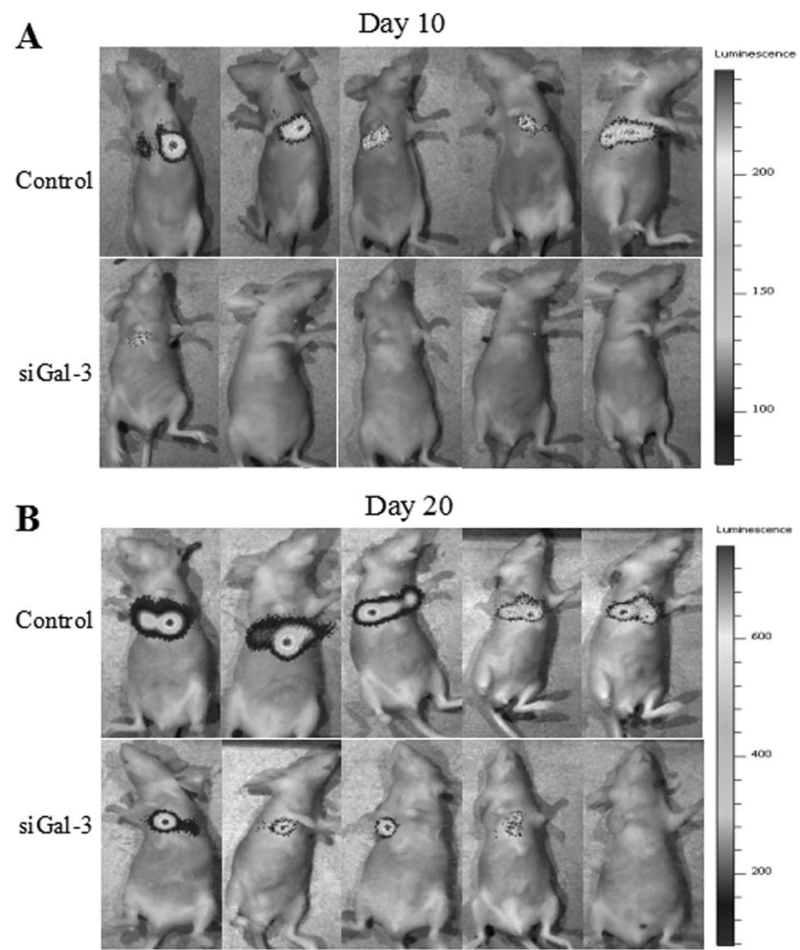

Fig. 10 Downregulation of Gal-3 inhibited pulmonary metastasis of A549 cells in nude mice. a-c A549-Luc cells which were transfected with siGal-3 or control siRNA were injected into nude mice via tail

$[36,44]$, which could be induced by activated $\beta$-catenin/ LEF-1 signaling pathway directly [45]. However, the transcriptional mechanism of $\mathrm{N}$-cadherin remains unclear. In this study, Gal-3 expression suppression decreased $\beta$-catenin expression both in cytoplasm and in nucleus, indicating that endogenous Gal-3 promoted nuclear accumulation of $\beta$ catenin. This result was consistent with early studies $[5,46]$. $\mathrm{N}$-cadherin expression was downregulated by either endogenous Gal-3 suppression or exposure to $\beta$-catenin/TCFmediated transcription inhibitor ICG-001 in A549 cells. Furthermore, endogenous Gal-3 suppression could not downregulate the expression of $\mathrm{N}$-cadherin in the presence of ICG-001. These results indicate that endogenous Gal-3 upregulates the expression of $\mathrm{N}$-cadherin through promotion of nuclear translocation of $\beta$-catenin.

CD44 is a transmembrane glycoprotein expressed on various cell surfaces [47] and plays a crucial role in regulating adhesion of cell-cell and cell-ECM [48]. It promotes cancer metastasis in many cancers such as breast cancer, gastric cancer, colon cancer, and cervical cancer [49-52]. In addition, CD44 has been reported to be a target protein of $\mathrm{Wnt} / \beta$-catenin pathway $[51,53]$. In this study, suppression of endogenous Gal-3 expression was seen to decrease the expression of CD44, which was abolished by ICG-001. These indicated that the decreased expression of CD44 induced by Gal-3 suppression were dependent on the
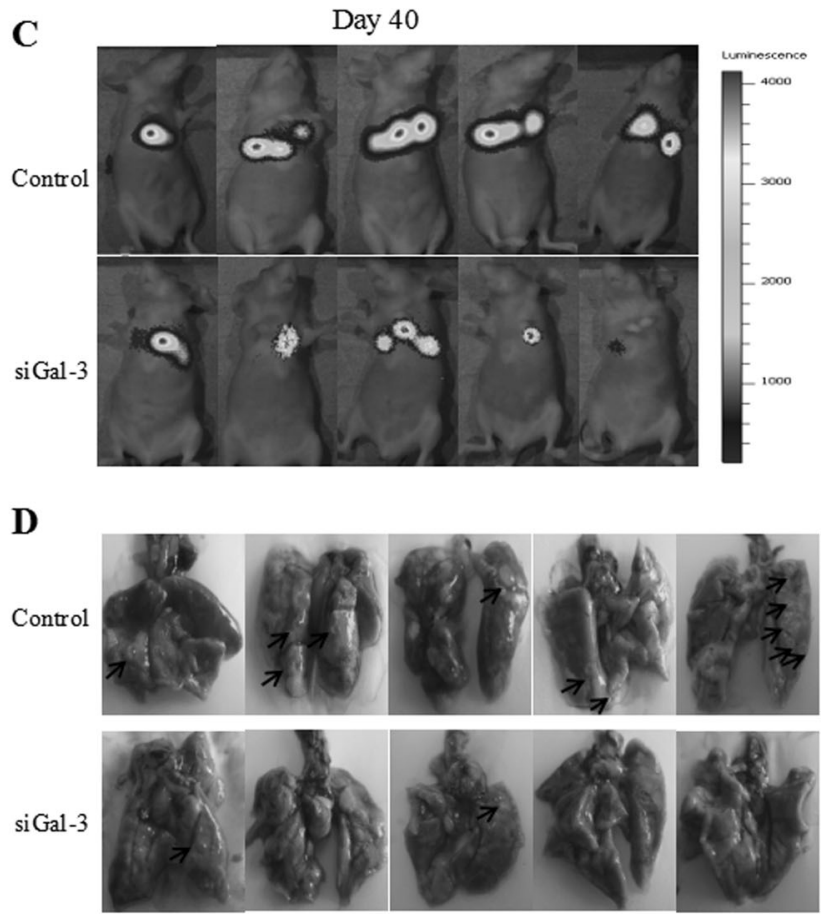

vein to observe lung metastasis in IVIS Imaging system at days 10, 20, 40. d Macroscopic appearance of lungs at day 40 after tumor cell injections. Arrows, metastatic foci

presence of $\beta$-catenin. However, the expression of CD44 showed no significant change after treatment with ICG-001 to inhibit the activity of $\beta$-catenin/TCF-mediated transcription, suggesting that there may be other regulatory mechanism of CD44 transcription which is $\beta$-cateninindependent.

In this study, endogenous Gal-3 was observed to promote migration and invasion of A549 cells depending on $\beta$ catenin/TCF transcriptional activity. A combined treatment of the cells with ICG-001 and siGal-3 produced a synergistic inhibition on A549 cell invasion and migration. This implied that $\beta$-catenin/TCF transcriptional activity played an important role in Gal-3 induced migration and invasion. Both N-cadherin and CD44 have been shown previously to promote tumor cell migration and invasion [32-35, 38, 50, 54], which was in consistence with the results shown in this study. The discovery that ICG-001 also inhibited the expression of MMP-9 and MMP-2 suggests that these MMP members may contribute to the migration and invasion of A549 cells induced by Gal-3/ $\beta$-catenin pathway.

A previous study has shown that exogenous Gal-3 increased tumor cell adhesion to HUVECs by binding to MUC1 on cell surface to expose small CAMs [11]. In this study, we observed the effect of recombinant Gal-3 on low MUC1-expressing PC-3M cells and A549 cell adhesion to HUVECs. Our results show that recombinant Gal-3 also 
increased low MUC1-expressing tumor cell adhesion to HUVECs, suggesting that other mechanisms being independent on MUC1 existed. An earlier study reported that exogenous Gal-3 could be rapidly internalized from the exogenous compartment by endocytosis in macrophages [26]. Therefore, we hypothesized that recombinant Gal-3 could be internalized in tumor cells via endocytosis. The current results verified this assumption that Gal-3 entered into the cytoplasm and nucleus of PC-3M cells and A549 cells by separating cytoplasm with nucleus and cytomembrane with cytoplasm. Furthermore, our results show that $\beta$ catenin was increased in cytoplasm and nucleus of PC-3M cells and A549 cells after incubation with recombinant Gal3. Once $\beta$-catenin/TCF-mediated transcription was inhibited by the presence of ICG-001, the increase of recombinant galectin-3-mediated cell adhesion was reduced. These indicated that exogenous Gal-3 upregulated cancer cell adhesion to HUVECs also partly depending on nucleus accumulation of $\beta$-catenin as the same as endogenous Gal-3. In addition, recombinant Gal-3 significantly increased the expression of $\mathrm{N}$-cadherin and CD44 in either PC-3M cells or A549 cells, while could not regulate the expression of these two CAMs in the presence of ICG-001, suggesting that exogenous Gal-3 upregulated the expression of $\mathrm{N}$ cadherin and CD44 in both A549 cells and PC-3M cells through promoting $\beta$-catenin/TCF-mediating transcription. What's more, A549 cell adhesion to HUVECs was inhibited by suppression of $\mathrm{N}$-cadherin and $\mathrm{CD} 44$, increased after treatment with recombinant $\mathrm{Gal}-3$ by upregulating the expression of these two CAMs, further indicating that exogenous Gal-3 promoted cancer cell adhesion to HUVECs by increasing the expression of $\mathrm{N}$-cadherin and $\mathrm{CD} 44$ in the presence of $\beta$-catenin.

In conclusion, exogenous as well as endogenous Gal-3 promotes cancer cell adhesion to vascular endothelial cells by increasing the expression of $\mathrm{N}$-cadherin and $\mathrm{CD} 44$ via an increase of $\beta$-catenin nuclear accumulation. Moreover, the effect of endogenous Gal-3 on the metastasis of A549 cells with low expression of MUC1 was confirmed in vivo. This indicates a new molecular mechanism of Gal-3-mediated cell adhesion in cancer metastasis and may have therapeutic potential for developing new strategies to prevent metastasis.

Acknowledgements This work was funded by the National Science Foundation of China Grants (81373450), the Major Project of Science and Technology of Shandong Province (2015ZDXX0301A03), and the Fundamental Research Funds of Shandong University (2016JC032).

\section{Compliance with ethical standards}

Conflict of interest The authors declare that they have no conflict of interest.

\section{References}

1. Ho MK, Springer TA. Mac-2, a novel 32,000 Mr mouse macrophage subpopulation-specific antigen defined by monoclonal antibodies. J Immunol. 1982;128:1221-8.

2. Liu F, Rabinovich GA. Galectins as modulators of tumour progression. Nat Rev Cancer. 2005;5:29-41.

3. Ochieng J, Green B, Evans S, James O, Warfield P. Modulation of the biological functions of galectin-3 by matrix metalloproteinases. Biochim Biophys Acta. 1998;1379:97-106.

4. Ochieng J, Warfield P, Green-Jarvis B, Fentie I. The role of Galectin-3 in the interactions between breast carcinoma cells and elastin. J Cell Biochem. 2000;75:505-14.

5. Yu L. Circulating galectin-3 in the bloodstream: An emerging promoter of cancer metastasis. World J Gastrointest Oncol. 2010;2:177-80.

6. Dumic J, Dabelic S, Flogel M. Galectin-3: an open-ended story. Biochim Biophys Acta. 2006;1760:616-35.

7. Fukushi J, Makagiansar IT, Stallcup WB. NG2 proteoglycan promotes endothelial cell motility and angiogenesis via engagement of galectin-3 and alpha3beta1 integrin. Mol Biol Cell. 2004;15:3580-90.

8. Song S, Mazurek N, Liu C, Sun Y, Ding Q, Liu K, et al. Galectin3 mediates nuclear beta-catenin accumulation and Wnt signaling in human colon cancer cells by regulation of glycogen synthase kinase-3beta activity. Cancer Res. 2009;69:1343-9.

9. Iurisci I, Tinari N, Natoli C, Angelucci D, Angeluicci D, Cianchett E. Concentrations of galectin-3 in the sera of normal controls and cancer patients. Clin Cancer Res. 2000;6:1389-93.

10. Barrow H, Rhodes JM, Yu L. Simultaneous determination of serum galectin-3 and -4 levels detects metastases in colorectal cancer patients. Cell Oncol. 2013;36:9-13.

11. Yu L, Andrews N, Zhao Q. Galectin-3 interaction with ThomsenFriedenreich disaccharide on cancerassociated MUC1 causes increased cancer cell endothelial adhesion. J Biol Chem. 2007;282:773-81.

12. Zhao Q, Barclay M, Hilkens J, Guo X, Barrow H, Rhodes JM, et al. Interaction between circulating galectin-3 and cancer-associated MUC1 enhances tumour cell homotypic aggregation and prevents anoikis. Mol Cancer. 2010;9:154.

13. Nangia-Makker P, Honjo Y, Sarvis R, Akahani S, Hogan V, Pienta K, et al. Galectin-3 induces endothelial cell morphogenesis and angiogenesis. Am J Pathol. 2002;156:899-909.

14. Boscher C, Zheng Y, Lakshminarayan R, Johannes L, Dennis J W, Foster LJ, et al. Galectin-3 protein regulates mobility of N-cadherin and GM1 ganglioside at cell-cell junctions of mammary carcinoma cells. J Biol Chem. 2012;287:32940-52.

15. Lagana A, Goetz JG, Cheung P, Raz A, Dennis JW. Galectin binding to Mgat5-modified N-glycans regulates fibronectin matrix remodeling in tumor cells. Mol Cell Biol. 2006;26:3181-93.

16. Kuwabara I, Liu F. Galectin-3 promotes adhesion of human neutrophils to laminin. J Immunol. 1996;156:3939-44.

17. Warfield PR, Makker PN, Raz A, Ochieng J. Adhesion of human breast carcinoma to extracellular matrix proteins is modulated by galectin-3. Invas Metast. 1997;17:101-12.

18. Friedrichs J, Manninen A, Muller DJ, Helenius J. Galectin-3 Regulates Integrin alpha(2)beta(1)-mediated Adhesion to Collagen-1 and -IV. J Biol Chem. 2008;283:32264-72.

19. Zhao Q, Guo X, Nash G, Stone PC, Hilkens J, Rhodes JM, et al. Circulating galectin-3 promotes metastasis by modifying MUC1 localization on cancer cell surface. Cancer Res. 2009;69:6799806.

20. Chung L, Tang S, Wu Y, Sun GH, Liu HY, Sun KH. Galectin-3 augments tumor initiating property and tumorigenicity of lung 
cancer through interaction with ß-catenin. Oncotarget 2017; 6:4936-52.

21. Deutscher SL, Figueroa SD, Kumar SR. Tumor targeting and SPECT imaging properties of an In-111-labeled galectin-3 binding peptide in prostate carcinoma. Nucl Med Biol. 2009;36:13746.

22. Gao J, McConnell MJ, Yu B, Li JN, Balco JM, Black EP, et al. MUC1 is a downstream target of STAT3and regulates lung cancer cell survival and invasion. Int J Oncol. 2009;35:337-45.

23. Joshi MD, Ahmad R, Yin L, Raina D, Rajabi H, Bubley G, et al. MUC1 oncoprotein is a druggable target in human prostate cancer cells. Mol Cancer Ther. 2009;8:3056-65.

24. Emami KH, Nguyen C, Ma H, Kim DH, Jeong KW, Eguchi M, et al. A small molecule inhibitor of bcatenin/CREB-binding protein transcription. Proc Natl Acad Sci USA. 2004;101:12682-7.

25. Takahashi-Yanaga F, Kahn M. Targeting Wnt signaling: can we safely eradicate cancer stem cells? Clin Cancer Res. 2010;16:3153-62.

26. Lepur A, Carlsson MC, Novak R, Dumic J, Nillson UJ, Leffler H. Galectin-3 endocytosis into macrophages by carbohydrate independent and dependent pathways. Biochim Biophys Acta. 2012;1820:804-18.

27. Xue J, Gao X, Fu C, Cong Z, Jiang H, Wang W, et al. Regulation of galectin-3-induced apoptosis of Jurkat cells by both O-glycans and N-glycans on CD45. Febs Lett. 2013;587:3986-94.

28. Merlin J, Stechly L, de Beauce S, DMonté D, Leteurtre E. Galectin-3 regulates MUC1 and EGFR cellular distribution and EGFR downstream pathways in pancreatic cancer cells. Oncogene. 2011;30:2514-25.

29. Piyush T, Chacko AR, Sindrewicz P, Hilkens J, Rhodes JM, Yu LG. Interaction of galectin-3 with MUC1on cell surface promotes EGFR dimerization and activation in human epithelial cancer cells. Cell Death Differ. 2017;24:1937-47.

30. Michel AK, Nangiamakker P, Raz A, Cloninger MJ. Lactosefunctionalized dendrimers arbitrate the interaction of galectin-3/ MUC1 mediated cancer cellular aggregation. Chembiochem. 2014; 15:2106-12.

31. Sparks AB, Morin PJ, Vogelstein B, Kinzler KW. Mutational analysis of the APC/beta-catenin/Tcf pathway in colorectal cancer. Cancer Res. 1998;58:1130-4.

32. Jennbacken K, Tesan T, Wang W, Gustavsson H, Damber JE, Welen K. N-cadherin increases after androgen deprivation and is associated with metastasis in prostate cancer. Endocr Relat Cancer. 2010;17:469-79.

33. Nagi C, Guttman M, Jaffer S, Qiao R, Keren R, Triana A. Ncadherin expression in breast cancer: correlation with an aggressive histologic variant-invasive micropapillary carcinoma. Breast Cancer Res Treat. 2005;94:225-35.

34. Yang Z, Zhang X, Gang H, Li X, Li Z, Wang T, et al. Upregulation of gastric cancer cell invasion by Twist is accompanied by $\mathrm{N}$-cadherin and fibronectin expression. Biochem Bioph Res Commun. 2007;358:925-30.

35. Zhuo H, Jiang K, Dong L, Zho Y, Lv L, Lv Y, et al. Overexpression of $\mathrm{N}$-cadherin is correlated with metastasis and worse survival in colorectal cancer patients. Chinese Sci Bull. 2013;58:3529-34.

36. Nakajima S, Doi R, Toyoda E, Tsuji S, Wada M. N-cadherin expression and epithelial-mesenchyma ltransition in Panereatic cancer. Clin Cancer Res. 2004;10:4125-33.
37. Yoshinaga $\mathrm{K}$, Inoue $\mathrm{H}$, Utsunomiya $\mathrm{T}$, Sonoda $\mathrm{H}$, Masuda $\mathrm{T}$, Mimori $\mathrm{K}$, et al. N-cadherin is regulated by activin A and associated with tumor aggressiveness in esophageal carcinoma. Clin Cancer Res. 2004;10:5702-7.

38. Li G, Satyamoorthy K, Herlyn M. N-cadherin mediated intercellular interactions Promote survival and migration of melanoma cells. Cancer Res. 2001;61:3819-25.

39. De WO, Westbroek W, Verloes A, Bloemen N, Brack M Gespach $\mathrm{C}$, et al. Critical role of N-cadherin in myofibroblast invasion and migration in vitro stimulated by colon-cancer-cellderived TGF-beta or wounding. J Cell Sci. 2004;117:4691-703.

40. Theisen CS, Johnson KR, Wheelock MJ. NHERF links the Ncadherin/catenin complex to the plateletderived growth factor receptor to modulate the actin cytoskeleton and regulate cell motility. Mol Bio Cell. 2007;18:1220-32.

41. Tran NL, Nagle RB, Cress AE, Heimark RL. N-cadherin expression in human prostate carcinoma cell lines: an epithelialmesenchymal transformation mediating adhesion with stromal cells. AM J Pathol. 1999;155:787-98.

42. Hazan RB, Phillips GR, Qiao R, Norton L, Aaronson SA. Exogenous expression of $\mathrm{N}$-cadherin in breast cancer cells induces cell migration, invasion, and metastasis. $\mathrm{J}$ Cell Biol. 2000;148:779-90.

43. Zucker S, Vacirca J. Role of matrixmetalloproteinases (MMPs) in colorectalcancer. Cancer Metast Rev. 2004;23:101-17.

44. Turley EA, Veiseh M, Radisky DC, Bissell MJ. Mechanisms of disease: epithelial-mesenchymal transition-does cellular plasticity fuel neoplastic progression? Nat Clin Pract Onc. 2008; 5:280-90.

45. Kim K, Lu Z, Hay ED. Direct evidence for a role of beta-catenin/ LEF-1 signaling pathway in induction of EMT. Cell Biol Int. 2002;26:463-76.

46. Shimura T, Takenaka Y, Tsutsumi S, Hogan V, Kikuchi A, Raz A, et al. Galectin-3, a novel binding partner of beta-catenin. Cancer Res. 2004;64:6363-7.

47. Sneath RJ, Mangham DC. The normal structure and function of CD44 and its role in neoplasia. Mol Pathol. 1998;51:191-200.

48. Goodison S, Urquidi V, Tarin D. CD44 cell adhesion molecules. Mol Pathol. 1999;52:189-96.

49. Herrera-Gayol A, Jothy S. Adhesion proteins in the biology of breast cancer: Contribution of CD44. Exp Mol Pathol. 1999;66:149-56.

50. Jang B, Li Y, Graham DY, Cen P. The role of CD44 in the pathogenesis, diagnosis, and therapy of gastric cancer. Gut Liver 2011;5:397-405.

51. Wielenga VJM, Smits R, Korinek V, Smit L, Kielman M, Fodde $\mathrm{R}$, et al. Expression of CD44 in Apc and Tcf mutant mice implies regulation by the WNT pathway. AM J Pathol. 1999;154:515-23.

52. Kainz C, Kohlberger P, Tempfer C, Sliutz G, Gitsch G. Prognostic value of CD44 splice variants in human stage III cervical cancer. Eur J Cancer. 1995;31A:1706-9.

53. Högerkorp CM, Bilke S, Breslin T, Ingvarsson S, Borrebaeck CAK. CD44-stimulated human B cells express transcripts specifically involved in immunomodulation and inflammation as analyzed by DNA microarrays. Blood. 2003;101:2307-13.

54. Wielenga VJM, van der Neut R, Offerhaus GJA, Pals ST. CD44 glycoproteins in colorectal cancer: expression, function, and prognostic value. Adv Cancer Res. 2000;77:169-87. 